\title{
Agent-as-a-Service-based Geospatial Service Aggregation in the Cloud: A Case Study of Flood Response
}

\author{
Xicheng Tan ${ }^{a}$, Liping $\mathrm{Di}^{\mathrm{b},{ }^{*}}$, Meixia Deng ${ }^{b}$, Fang Huang ${ }^{c, d}$, Xinyue $\mathrm{Ye}^{\mathrm{e}}$, \\ Zongyao Sha ${ }^{a}$, Ziheng Sun ${ }^{b}$, Weishu Gong ${ }^{b}$, Yuanzheng Shao ${ }^{a}$, Cheng Huang ${ }^{a}$
}

a International School of Software, Wuhan University. 37 Luoyu Road, Wuhan, 430079, China. b Center for Spatial Information Science and Systems, George Mason University, Fairfax, VA 22030, USA. cSchool of Resources \& Environment, University of Electronic Science and Technology of China, 2006 Xiyuan Ave., Chengdu 611731, China d Institute of Remote Sensing Big Data, Big Data Research Center, University of Electronic Science and Technology of China, 2006 Xiyuan Ave., Chengdu 611731, China.

e, Department of Geography, Kent State University, Kent, OH 44242, USA.

\begin{abstract}
An Agent-as-a-Service (AaaS)-based geospatial service aggregation is proposed to build a more efficient, robust and intelligent geospatial service system in the Cloud for flood emergency response. It involves an AaaS infrastructure, encompassing the mechanisms and algorithms for geospatial Web Processing Service (WPS) generation, geoprocessing and aggregation. The method has the following advantages: 1) it allows separately hosted services and data to work together, avoiding transfers of large volumes of spatial data over the network; 2 ) it enriches geospatial service resources in the distributed environment by utilizing the agent cloning, migration and service regeneration capabilities of the AaaS, solving issues associated with lack of geospatial services to a certain extent; 3 ) it enables the migration of services to target nodes to finish a task, strengthening decentralization and enhancing the robustness of geospatial service aggregation; and 4) it helps domain experts and authorities solve interdisciplinary emergency issues using various Agent-generated geospatial services.
\end{abstract}

Keywords: Geospatial Service; Service Aggregation; Open Geospatial Consortium (OGC); $X$-as-a-Service; Cloud Computing; Agent; Flood Response

* corresponding author

\section{Introduction}

Natural and environmental disasters (flood, earthquake, pollution, and etc.) frequently occur and endanger lives and cause tremendous losses across the globe each year. In China, flood 
is one of the most frequent and serious disasters because $50 \%$ of the population and over $2 / 3$ of the agricultural and industrial products of China come from flood-prone regions (Luo et al., 2007). To save lives and reduce economic losses during flood events, the Flood Control and Drought Relief Office (FCDRO) of the central and provincial governments of China must make rapid, effective and appropriate decisions when responding to these emergencies, such as population evacuation, temporary settlement, dike repair and enhancement, and utilization of flood diversion areas. This decision-making process involves experts and decision makers from various authorities and organizations who are responsible for flood control, agriculture, forestry, water resources and hydrology, land resources, transportation, medical treatment, and disaster relief. Generally, authorities and organizations involved in this decision-making process have domain-specific geospatial data, services, algorithms and models. Traditionally, during flood emergencies, FCDRO must collect and combine all the required data from those sources. Based on the data, the FCDRO organizes all relevant personnel to discuss and evaluate each situation and establish the "best" flood response scheme. The FCDRO will then communicate the appropriate actions that responsible agencies should conduct in a top-down manner. Finally, all responsible parties will conduct the flood control and mitigation actions according to the scheme. Unfortunately, this process is usually time consuming and labor intensive and is not suitable for real-time decision making. Real-time decisions are required when a situation is urgent or when a new situation occurs during the action, requiring an immediate response. In these scenarios, the traditional decision-making process will not allow the FCDRO enough time to develop an effective strategy.

An effective disaster prevention and reduction decision support system can assist decision makers in developing rapid and sound decisions during disasters. In the 1990s and early 2000s, many centralized disaster prevention and reduction systems were established to assist decision makers. These systems manually collected required data in advance and stored them in a database. Therefore, it was difficult to acquire the latest distributed geospatial data using these systems. As mentioned above, the most accurate data often belong to professional authorities and organizations, and a lengthy process is required to incorporate data into these systems to support decision making by the FCDRO. Furthermore, these systems are unable to rapidly upgrade to better algorithms or models. Consequently, disaster prevention and reduction systems based on the centralized approach cannot satisfy requirements associated with supporting decision making, notably, during emergencies.

Compared to centralized approach-based systems, disaster prevention and reduction systems based on distributed approaches (e.g., Service Oriented Architecture (SOA)) generally exhibit better capabilities. In SOA-based systems, geospatial resources are retained in distributed nodes, and such systems can use these distributed geospatial resources through standard geospatial services (i.e., Open Geospatial Consortium (OGC) Web Services, including the Web Map Service (WMS), Web Feature Service (WFS), Web Coverage Service (WCS) and Web Processing Service (WPS)). To solve complex tasks, the individual services are typically aggregated into a composite service. In this manner, the distributed geospatial resources can easily be integrated into a disaster prevention and reduction system to support 
decision making. As a result, the SOA-based method has played a considerable role in supporting decision making over the past decade.

However, in traditional SOA-based systems, all services are built and published in a fixed manner in the webserver, making it difficult to move such services from one server to another. Additionally, it can be challenging or even impossible to automatically migrate services while processes are taking place. As a result, the traditional SOA-based method faces challenges such as the low transfer efficiency of large-volume spatial data and service node failure, which reduce the efficiency and robustness of service aggregation. Moreover, experts from different domains are involved in different phases of emergency and disaster response activities. Traditional SOA-based geospatial service aggregation requires experts from different domains to build individual services. This requirement implies that domain experts must also become familiar with geospatial services (e.g., OGC Web Services specifications), which is typically difficult for experts, especially when issues span multiple disciplines. Thus, it is necessary to take advantage of SOA engineering (Bræk et al., 2005; Sawyer et al., 2005; Usländer et al., 2010) to optimize the SOA-based method, allowing experts to focus on their own domains without having to become geospatial service experts, thereby optimizing the participation of domain experts (Leskens et al., 2014).

Drawbacks of the traditional SOA-based method can be overcome by agents, which are capable of flexible, autonomous actions and migration across different environments to meet designed objectives (Jennings, 2000). Cloud computing highlights the merits of agents, as the Cloud facilitates the configuration of agent environments across a distributed network. This allows agents to migrate and compute autonomously throughout the distributed environment. Cloud- and Agent-based methods can solve several challenges associated with applying the traditional SOA-based method (Tan et al., 2015). However, the agent designed by Tan et al. (2015) communicated in a non-standard manner (e.g., invoking ResultWFS and ResultWCS services to return results), limiting its capability and applicability. To overcome limitations in existing methods, a new Agent-as-a-Service (AaaS)-based service aggregation method is presented in this paper. This method aims to capitalize on the geoprocessing service capabilities of agents, optimize the efficiency and robustness of composite geospatial services, enrich feasible geospatial service resources in distributed environments, and resolve issues of non-standard communication between agents while promoting the participation of domain experts and authorities. The feasibility of the AaaS-based method is demonstrated and evaluated through a flood response prototype system, which effectively and efficiently helps the decision makers, authorities and domain experts to collaborate together during disaster responding. Moreover, this research also offers new idea and perspective to the existing disaster response mechanisms (Alongi et al., 2004; Tralli et al., 2005; Quinn et al., 2007; Dokas et al., 2009; Van et al., 2010; Xu et al., 2014; Kauker et al., 2016) and environmental decision making approaches (Bianconi et al., 2004; Voinov et al., 2010; Samarasinghe et al., 2013; Rajib et al., 2015). 


\section{Related Work}

\subsection{Disaster Response Research}

Numerous studies of disaster response (such as for floods, earthquakes, hurricanes, tsunamis, etc.) have been conducted in the past two decades, and many of them are based on centralized GIS systems (Brivio et al., 2002; Thumerer et al., 2000; ZHOU, et al., 2000; Taramellia et al., 2010; Yu et al., 2012). Because of the shortcomings of centralized disaster decision support GIS systems, researchers in the geosciences have established Distributed Geographic Information Processing (DGIP)-based methods, such as SOA, Federal Enterprise Architecture (FEA)-based DGIP architecture and spatial service chains (Di, 2004; Di et al., 2006; Zhao et al., 2007; 2009; Yang, 2009; Deng and Di, 2009, 2010). New methodologies in information and communications technologies (ICTs) have been used to build early warning systems for tsunami detection (Wächter et al., 2012). A grid-based SOA-supported disaster management mechanism was proposed to solve heterogeneity, distribution, and efficiency issues and further the ability of the government to manage disasters (Chen et al., 2009; Fang et al., 2009). To estimate potential storm damage, an ontology-based distributed geospatial service finding method was proposed to search for services in the distributed environment and apply the services to disaster management (Klien et al., 2005). A flexible SOA-based framework was proposed for environmental crisis management decision support to assist in decision making during emergencies (Vescoukis et al., 2012). Cloud computing and SOA methods were explored to address communication problems among authorities during the emergency rescue process (Lehto et al., 2012). The use of utility Cloud services and SOA in public protection and disaster relief (PPDR) operations has been investigated, and the benefits of the standardized PPDR SOA were evaluated (Rajamäki et al., 2014).

\subsection{Geospatial Service Aggregation}

Researchers in computer science have developed service aggregation theories and methodologies (Sivashanmugam et al. 2004; Arpinar et al., 2005; Oh et al., 2007; Hwang et al., 2008; Huang et al., 2009; Hadad et al., 2010). Based on OGC Web Services specifications, studies of spatial service aggregation have been conducted (Deng et al., 2004; Di, 2005; Sayar et al., 2005; Di et al., 2006; Yue et al., 2007; Deng and Di, 2010; Yu et al., 2012). Based on OGC Web Services specifications regarding data services (e.g., WMS, WCS, and WFS) (Swain et al., 2015; Sadler et al., 2016) and geoprocessing services (e.g., WPS) (Castronova et al., 2013), service aggregation mechanisms have been proposed to solve practical problems, mainly adopting Service-Oriented Architectures (SOA) (Pasley et al., 2005; Schroth et al., 2007; Oz et al., 2012; Deng et al., 2012, 2013; Peng et al., 2015). Problems associated with geospatial service chains were addressed through system architecture studies that implemented complex geoprocessing models and workflows using Web Service Orchestration (WSO) and OGC Web Services specifications (Di, 2005; Yue et al., 2007; Deng 
and $\mathrm{Di}, 2013)$. OGC specifications were widely adopted to construct service chains in various applications, such as wild forest fire risk management and detection (Christensen, 2009; Chen et al., 2010). A geospatial semantics-supported SOA approach was proposed to illustrate how ontology-based geospatial semantics are used to enable automatic geospatial service discovery, access, and chaining (Di et al., 2006; Yue et al., 2007, Zhao et al., 2009). A service geoprocessing workflow was proposed to generate raw data, geospatial products, and sensor maps (Chen et al., 2010). A construction method for a geoprocessing e-Science workflow model was proposed to integrate logical and physical processes into a composite process service chain for sensor observations (Chen et al., 2012). Researchers designed and implemented a geoprocessing Appstore that can share geoprocessing algorithms throughout a community and can support the construction and execution of geospatial workflows based on the SOA method (Henzen, 2015).

\subsection{XaaS in Cloud Computing}

Cloud computing refers to the use of hardware and software that are delivered as a service over a network and is a type of Internet-based computing. Cloud computing is also known as 'on-demand computing,' where shared resources, data and information are provided to computers and other devices based on their requests. Cloud computing offers flexible infrastructure, easy maintenance, efficient costs and high performance (Wang et al., 2010). The literature review by Yang et al. (2013) demonstrated that Cloud computing can assist in the development of a Digital Earth and in geoscience research. Although the definition of Cloud computing varies, a Cloud is generally expected to maintain three fundamental services: the infrastructure as a service (laaS) (Lloydab et al., 2012; Wan et al., 2014), the platform as a service (PaaS), and the software as a service (SaaS) (Mell \& Grance, 2011). Based on laaS, all resources (such as computing equipment, storage and networks) can be used as services, and because of the scalability of laaS, Cloud services can be used on demand. Therefore, the Cloud has become a new HPC platform, offering powerful virtual clusters (Wang et al., 2011; Huang et al., 2013). PaaS provides an on-demand computing platform. Commercial enterprises such as Microsoft and Google offer PaaS services to scale computing and storage resources automatically to match the demand of an application. Geoprocessing studies have been successfully implemented based on PaaS (Shao et al., 2011; Yue et al., 2012; Chen et al., 2012; Shao et al., 2012; Yang et al., 2012). SaaS provides software applications and databases and has been rapidly adopted for applications and services in software Clouds (Liu et al., 2010). In addition to the fundamental Cloud services, Everything as a Service (XaaS) studies have also been conducted (Wang et al., 2013; Xiong et al., 2014; Ben et al., 2014; Ibrahim et al., 2014; Bitterman et al., 2014). As an example of XaaS, a Model-as-a-Service (MaaS) was designed and implemented to publish a global climate change model as a service in the Cloud (Li et al., 2014). Sensing-as-a-Service and sensor web technologies have been proposed to connect billions of sensors in the Cloud (Di et al., 2010), to collect real-time environmental data from the future Internet (Havlik et al., 2011) and to achieve efficient and effective resource management in Smart Cities (Perera et al., 2014). 


\subsection{Spatial Agent Method}

The concept of software agents can be traced back to Distributed Artificial Intelligence (DAI) in the 1970s. Carl Hewitt defined an agent as a concurrent Actor model of an interactive and concurrently executed object (Hewitt, 1977). In the 1980s and 1990s, it experienced rapid evolution and had numerous definitions that were not necessarily widely accepted by the Agent community (Nwana, 1996). Currently, Wikipedia defines a software agent as a computer program that acts for a user or other program in a relationship of agency, which is straightforward and adopted in this article. In general, four key features, including reaction to the environment, autonomy, goal orientation and persistence, distinguish agents from arbitrary programs (Franklin \& Graesser, 1996). Mobile Agent-based applications have been studied in multiple research projects (e.g., Gray et al., 2002; Parker et al., 2003). Two primary modes are available for Agent-based methods: the instrumental mode and the representational mode (Brown et al., 2006). Representational agents have been used to simulate the activities of a wide variety of entities, such as people, biological cells, animals and automobiles. Agent-based applications have been developed in the geosciences (Parker et al., 2003; Brown et al., 2009; Bithell et al., 2009; Schreinemachers et al., 2011; Dijkstra et al., 2011). Sengupta et al. (2003) evaluated, discussed and implemented a Multi-Agent-based decision-making system. Instrumental Agent-based methods have been used to optimize Web service aggregation and composition. A Multi-Agent-based coalition formation approach for service composition achieved a decentralized decision-making method (Muller et al., 2006). A mobile agent and active network-based Web service composition and aggregation framework was proposed to support service description, publishing, discovery, selection and composition (Xu et al., 2006). An agent can also be utilized to optimize the intelligence, efficiency and feasibility of distributed geographic information processing (DGIP) (Yang, 2009). An Agent-based environment has been developed to aggregate flexible Web-map services on the Internet (Wang et al., 2009). Via combination with service-oriented computing in the Cyberinfrastructure $(\mathrm{Cl})$, geographically aware intelligent agents (GAIA) were utilized to accomplish more efficient geoscience computation (Tang et al., 2011).

\section{Methodology}

This study utilizes Agent mobility to avoid moving large volumes of geospatial data across a network and implements automatic encapsulation of an agent into a geospatial service (i.e., Agent-generated service), invoking all of the agents based on OGC specifications. All of the agents can be built directly by domain experts. This section considers four major aspects: (1) AaaS infrastructure, (2) the WPS service generation mechanism, (3) geoprocessing rules for an Agent-generated WPS, and (4) the geospatial services aggregation algorithm. 


\subsection{AaaS Infrastructure}

It is difficult to execute a static WPS service when large volumes of geospatial data are retained in other nodes because of the limitations associated with data transfer. AaaS infrastructure is built on a Cloud computing environment. Agents, in the context of this paper, are defined as designed software programs that can migrate flexibly and perform specific actions associated with the generation and movement of WPS for defined purposes throughout the distributed Cloud environment. Agents are also capable of more autonomous actions (e.g., autonomous service availability optimization, etc.) for future purposes that are not covered in this study. The primary purposes of AaaS in this paper are as follows: (1) construct a universal environment for facilitating Agent computing mobility, (2) generate the WPS automatically, and (3) aggregate the geospatial services efficiently and robustly. Thus, requisite fundamental services must be available for these purposes.

The AaaS infrastructure is shown in Fig. 1. The AaaS infrastructure is a collection of web services, including Agent Registration, Agent Clone, Agent Migration, and Agent Life Detection. Users (e.g., domain experts) can register agents by calling an Agent Registration service (the mechanism will be described in detail in Section 3.2). Agents can move to target Cloud nodes when the Agent Migration service is requested by the service aggregation program (i.e., Service Aggregation Engine (SAE)) based on a service aggregation algorithm (illustrated in Section 3.4). Service generation regenerates WPS services by wrapping agents as soon as they are registered, allowing all agents to be invoked in a standard manner using OGC Web Services specification interfaces.

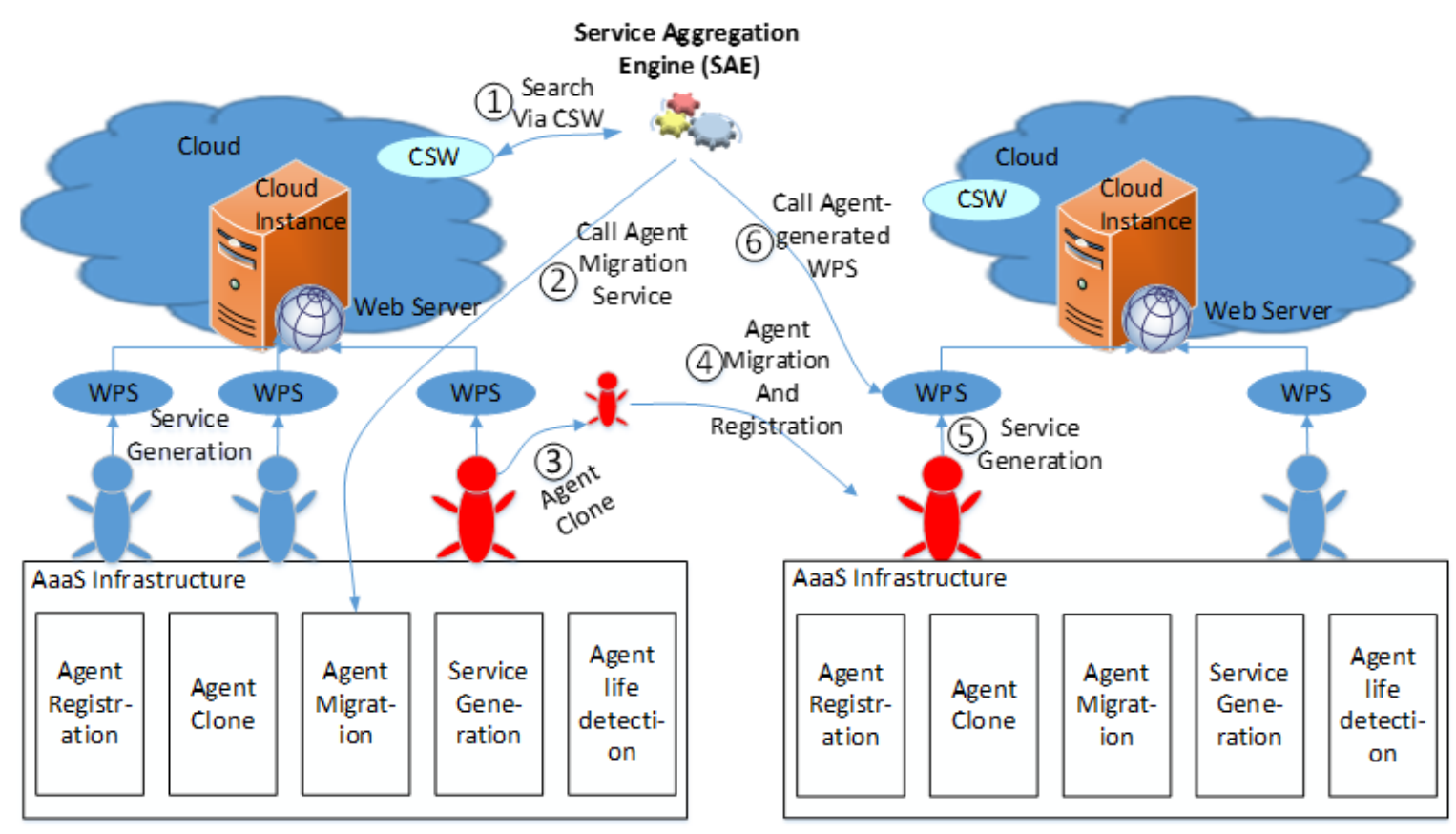

Fig. 1 The AaaS infrastructure

Fig. 1 also shows how an agent migrates and converts into a WPS service. When an application involves moving a WPS service to another node, the following steps should be 
taken: (1) the SAE should first search for the requisite WPS via CSW, and if the requisite WPS is found, the desired agent is located; (2) the SAE will immediately call an Agent Migration service in the source Cloud node to inform the AaaS infrastructure of the target Cloud node and that a desired agent must migrate, and the agents will detect the ID of the desired agent; (3) the agent with the same ID will then clone itself; (4) the agent will call the Agent Registration service in the target Cloud node to move its clone to the destination node and register it; (5) the new registered agent will then transform into a new WPS service via Service Regeneration; and (6) the regenerated WPS can be invoked through requests from the SAE, which keeps searching the CSW of the target Cloud node at a constant rate throughout this process. Over the course of this process, agents act autonomously and migrate across the Cloud via the AaaS infrastructure, which offers key capabilities for Agent computing. By contrast, the OGC Web Services (i.e., WPS and CSW) can only interact passively via http requests.

\subsection{WPS Service Generation Mechanism}

To simplify the participation of the users or domain experts, we designed a WPS service generation mechanism that assists in converting traditional standalone programs written by domain experts into agents and WPS services. The experts only need to build the programs that implement the following interface:

public Map<String, IData $>$ run(Map<String, List<IData $>>$ inputData) throws ExceptionReport

All of the geospatial data can be placed into inputData (a Map type in the Java programming language). String is a key of the values, and list<IData $>$ is a collection of the values. IData are abstract and can be assigned many datatypes, such as string, integer, and image. Because the interface is independent of geospatial service knowledge, this process assists domain experts in focusing on building computer programs according to domain-specific algorithms.

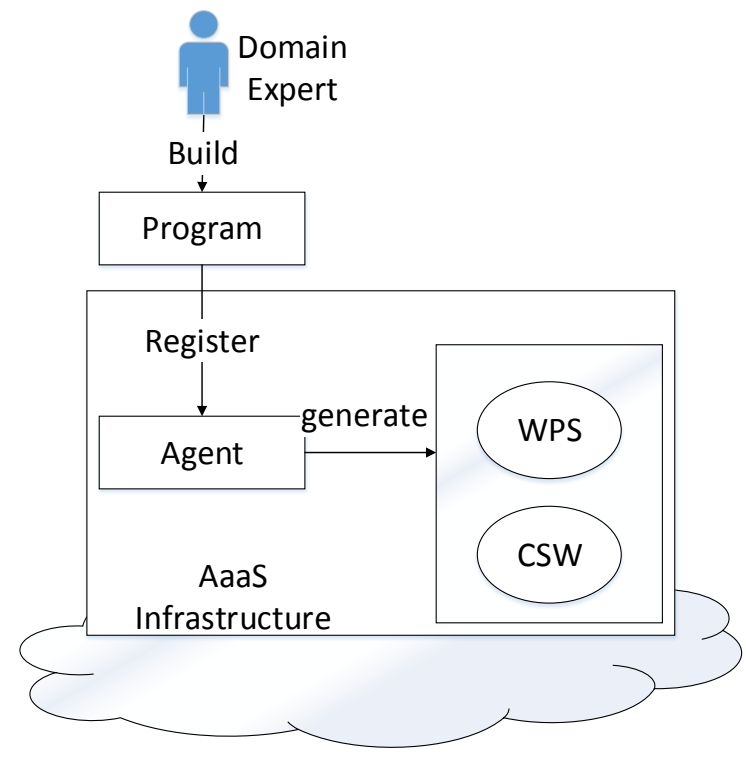

Fig. 2 WPS service generation mechanism

Fig. 2 shows that after a domain-specific program is built by a domain expert, the expert 
needs to upload the program to the AaaS infrastructure and then invoke the Agent Registration service to create a registered agent containing the program. The AaaS infrastructure will then generate WPS services for the registered agent by invoking the Service Generation service, and the Agent-generated WPS information will be added into the CSW catalogue service to assist in WPS service or agent search operations. After the programs are registered to the AaaS infrastructure, they can migrate to other nodes as mobile agents and assist the WPS service migration. The Agent-generated WPS can conduct geoprocessing according to the Geoprocessing Rules (Section 3.3), and the composite service can be executed according to the Geospatial Services Aggregating algorithm (Section 3.4).

\subsection{Geoprocessing Rules for Agent-generated WPS}

AaaS-based geoprocessing rules are established to allow the Agent-generated WPS to be executed in an intelligent and efficient manner using the mobile computing capability of the Agent. The AaaS-based geoprocessing rules are shown in Fig. 3.

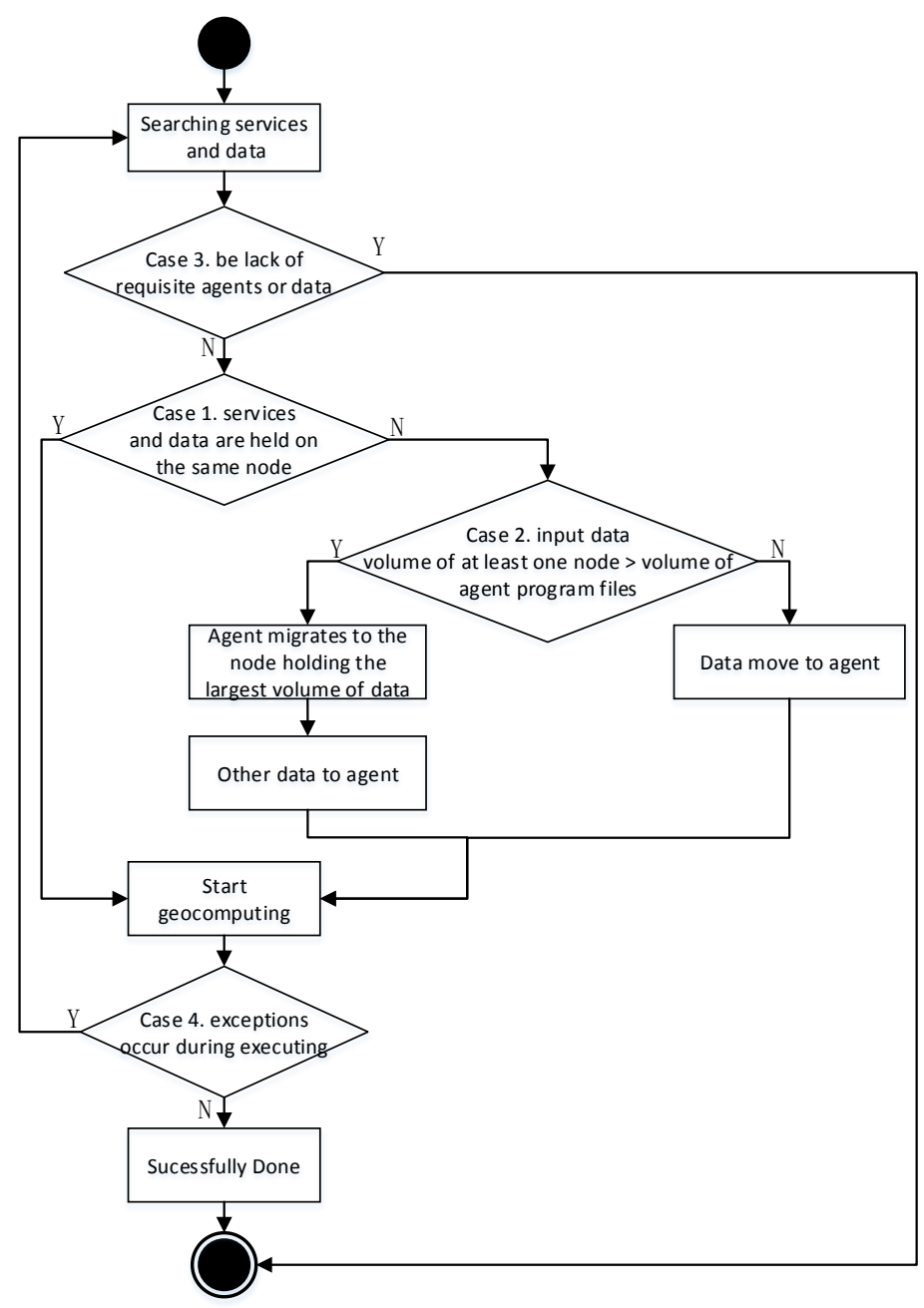

Fig. 3 The geoprocessing rules for an Agent-generated WPS

Fig. 3 shows the AaaS-based geoprocessing rules of the Agent-generated WPS, which are expected to cover the following four cases during the execution of the geoprocessing 
procedure:

Case 1: Both the geospatial data and WPS reside in one Cloud node. In this case, all of the geoprocessing and input data are held on identical servers. Therefore, the data will not be transferred and agents do not migrate;

Case 2: A service requires one or more data inputs hosted in different nodes. If volumes of input data held by individual nodes among all involved nodes are smaller than those of the agent program files, transferring the input data is preferred. If at least one node has a larger volume of input data than that of the agent, the agent will be migrated to the node that holds the largest volume of input data. Then, the other input data will be transferred from other nodes to the agent;

Case 3: A lack of requisite agents or data. In this case, the Agent-generated WPS will fail until requisite agents are registered and data become available;

Case 4: Exceptions occur during execution. If a node is invalidated by an agent life detection service during the execution of an Agent-generated WPS or a time-out exception occurs, the task will restart to recover the process.

\subsection{Geospatial Services Aggregation Algorithm}

A geospatial services aggregation algorithm is proposed for the SAE to aggregate the distributed geospatial services automatically. The algorithm is shown in Fig. 4.

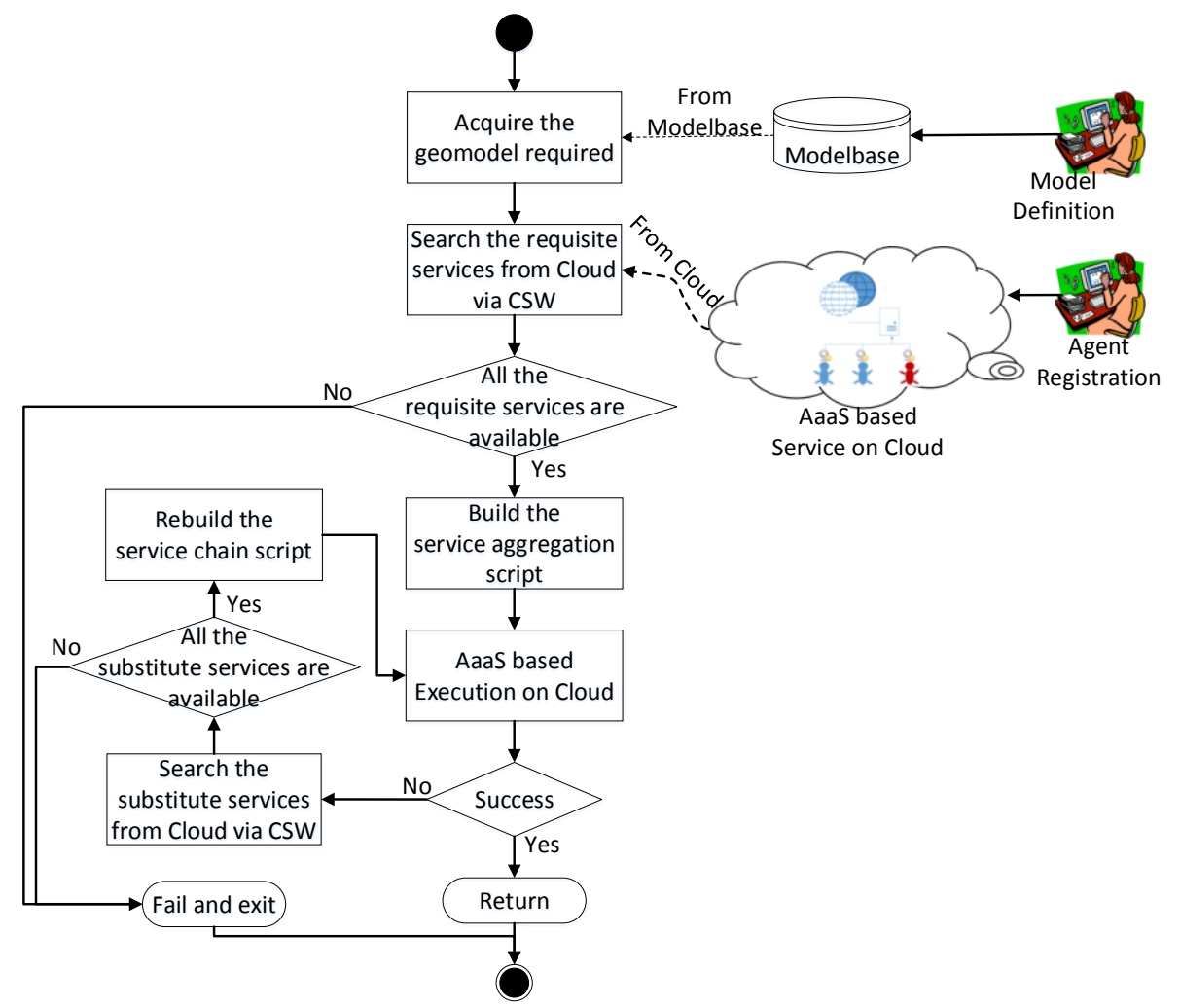


Fig. 4 Geospatial services aggregation algorithm

In this algorithm, after a geomodel has been selected from the modelbase (Tang et al., 2011) and submitted, the SAE will search for requisite services in Cloud nodes via CSW services and then construct the service aggregation script. A service aggregation script is created according to the geomodel, and the script specifies geospatial services, input data and output data for each atomic service (i.e., WPS) of the composite service. The SAE then executes atomic services according to the geoprocessing rules designated in Section 3.3 until the entire composite service succeeds or a service fails to execute. If a service fails to execute, the SAE will search for a substitute service from the Cloud nodes via the CSW, rebuild the service aggregation script and re-execute from the point where the last execution failed. However, if no substitutes can be used, the composite service will fail to execute and will be discarded.

When users wish to generalize the method for different geospatial applications, they must build the program based on the method presented in Section 3.2 and upload it to the system to complete registration. The WPS can then be generated and registered. After the aforementioned tasks have been completed, users can use the agent through the WPS. When geospatial service aggregation is required, the user must also use the SAE to execute composite services based on this geospatial services aggregation algorithm.

\section{Experiments and Analyses}

To evaluate the feasibility of AaaS-based geospatial service aggregation for flood response, we designed a flood response model according to a real world workflow and implemented a prototype system in the Alibaba Cloud (i.e., Aliyun) and the Amazon AWS Cloud separately. Both of these Clouds provide laaS, PaaS and SaaS services to users across the globe. The system performance was evaluated through comparative tests between the proposed approach and two other approaches, and the robustness of the approach was analyzed based on experiments.

\subsection{Flood Response Model}

We use the flood response of the Yangtze River Basin as a case study to verify the feasibility of the AaaS-based service aggregation method. To reduce the flood risk of the Yangtze River, dikes were constructed to separate selected areas as flood-diversion zones (FDZ). When the flood level of the river is higher than the warning level, a decision has to be made regarding whether the floodgates should be opened to discharge the flood water into the selected FDZs. Such a decision must consider the trade-off between residential and property losses in the FDZs and the possible losses caused by potential dike burst or overflow along the mainstream of the river if the FDZs are not used. In addition, decision makers must consider population evacuation, property transfers, food and medical resource supplies and agricultural losses in the FDZs when deciding to open the floodgates. 
Flood prevention and disaster relief is a systematic project involving many authorities and organizations. The authorities and organizations participating in disaster prevention and reduction include the FCDRO, Ministry of Land and Resources (MLR), Ministry of Transportation (MT), Ministry of Agriculture (MA), academic and research organizations (ARO), Bureau of Statistics (BS), Disaster and Emergency Relief Organization (DERO), Medical Aid Organization (MAO), Emergency Materials Supply Organization (EMSO) and Volunteer Organizations (VO). The responsibilities of these authorities are listed in Table 1.

TABLE 1

THE AUTHORITIES AND ORGANIZATIONS INVOLVED DURING FLOODING

\begin{tabular}{|c|c|}
\hline Authorities and Organizations & Duty \\
\hline $\begin{array}{l}\text { Flood Control and Drought } \\
\text { Relief Office (FCDRO) }\end{array}$ & $\begin{array}{l}\text { Collects real-time flood level data monitored by sensors in } \\
\text { hydrologic stations and organizes all useful resources to conduct } \\
\text { effective disaster prevention and reduction }\end{array}$ \\
\hline $\begin{array}{l}\text { Ministry of Land and Resources } \\
\text { (MLR) }\end{array}$ & Acquires high accuracy geographic data covering the flooding region \\
\hline Ministry of Transportation (MT) & $\begin{array}{l}\text { Manages high accuracy transportation data, including highway, } \\
\text { national road, provincial road, and county road data }\end{array}$ \\
\hline Ministry of Agriculture (MA) & $\begin{array}{l}\text { Manages numerous agricultural remote sensing data sets, including } \\
\text { multispectral and InSAR remote sensing data }\end{array}$ \\
\hline $\begin{array}{l}\text { Academic and research } \\
\text { organizations (ARO) }\end{array}$ & $\begin{array}{l}\text { Employ spatial analyses and remote sensing image interpretation } \\
\text { algorithms such as the flood submergence analysis, overlap analysis, } \\
\text { slope analysis, remote sensing image classification and crop } \\
\text { extraction algorithms, population transfer route analysis, and } \\
\text { resource (including medicine, emergency relief workers, food, tents } \\
\text { and volunteers) requirement analysis }\end{array}$ \\
\hline Bureau of Statistics (BS) & Collects pollution and economic data annually \\
\hline $\begin{array}{l}\text { Disaster and Emergency Relief } \\
\text { Organization (DERO) }\end{array}$ & Rescues and evacuates the population during flooding \\
\hline Medical Aid Organization (MAO) & Provides emergency medical services \\
\hline $\begin{array}{l}\text { Emergency Materials Supply } \\
\text { Organization (EMSO) }\end{array}$ & Delivers food, fresh water, and tents to people in the flood area \\
\hline $\begin{array}{l}\text { Volunteer } \\
\text { Organizations (VO) }\end{array}$ & Assist people in the disaster area \\
\hline
\end{tabular}

During flooding, the FCDRO establishes decisions for rescuing people; provides the population with the necessary medical aid, tents, food and fresh water; and analyzes the socioeconomic losses, e.g., agricultural, industrial, and property losses. According to the duties of the FCDRO, we designed a Flood Response Model, as shown in Fig. 5. 


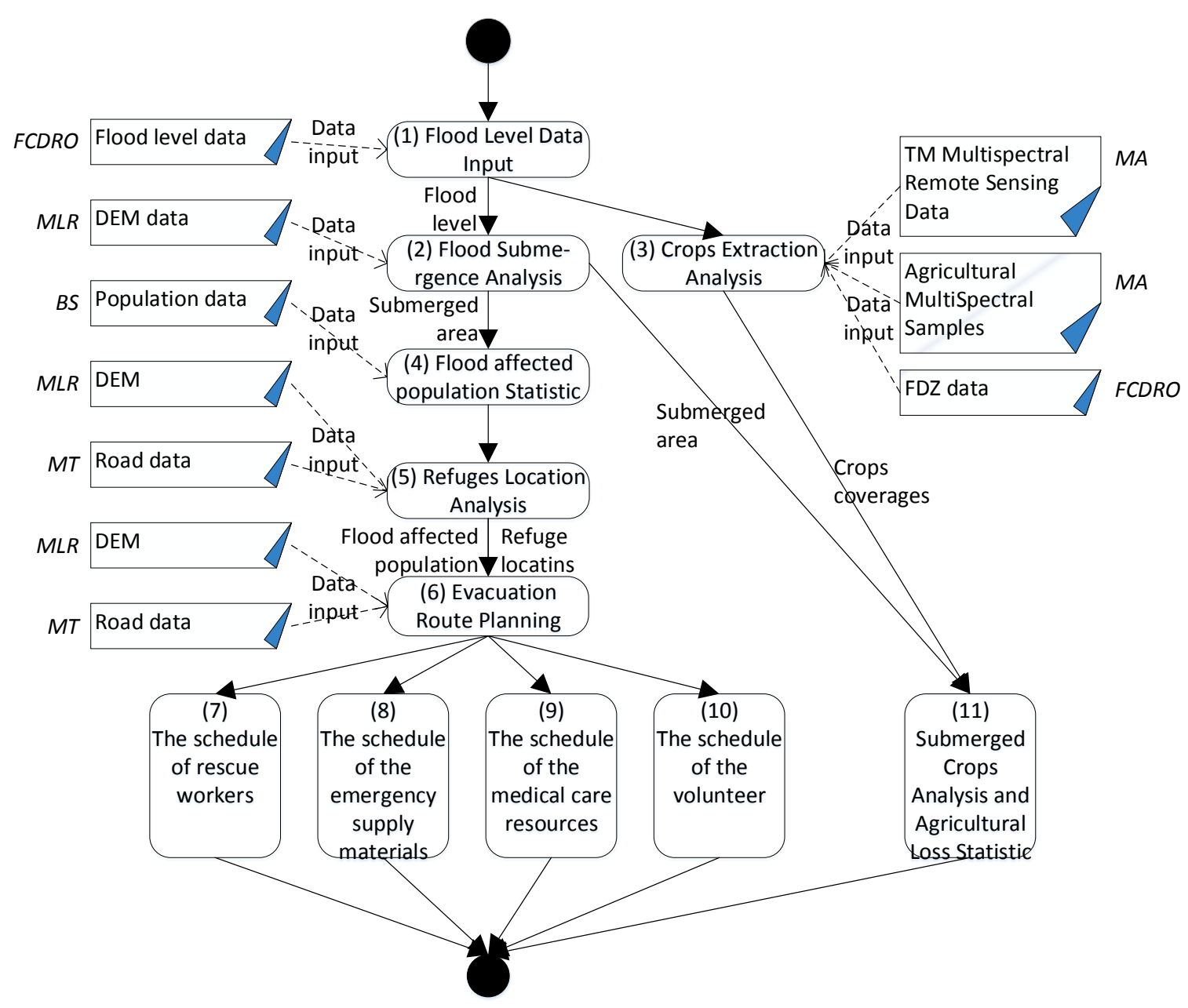

Fig. 5 Flood response model

This model includes the requisite analyses during flooding. Decision makers and participants can execute the model during flooding or at any time to simulate the flood response. After the flood level data are inputted by the system automatically or by the users manually, the composite service will begin to conduct the flood submergence analysis, the flood-affected population analysis, the refuge location analysis and evacuation route planning. Finally, the schedules of rescue workers, emergency supply materials, medical care resources, and volunteers will be synchronously established according to the flood-affected populations of the specific refuges. The submerged crop analysis and agricultural loss evaluation will be conducted after the flood submergence analysis and the crop extraction analysis.

\subsection{Prototype System}

To illustrate the procedures used to construct the AaaS geospatial service aggregation based on the methodology described above, we built a prototype system for flood response and implemented it in the Alibaba Cloud and the Amazon AWS Cloud. In total, six distributed single Cloud nodes are used in the system, and for each Cloud, an AaaS infrastructure and other requisite data are provided (detailed information is provided in Table 2). Table 2 shows the information related to the Cloud node ID, Cloud owner, retained agents, and data. The portal is built on Cloud 1. No original WPS is deployed in these Cloud nodes. However, the 
agents are registered in the AaaS infrastructure, and all registered agents will transform into WPS services automatically according to the WPS Service generation mechanism described in Section 3.2. To construct the prototype system in the Alibaba Cloud, we purchased six virtual machines (VMs) in different Cloud regions of the Alibaba Cloud and deployed the nodes listed in Table 2. We performed identical tasks in the AWS Amazon Cloud. The distributions of the nodes in the AWS and Alibaba Cloud are shown in Fig. 6.

TABLE 2

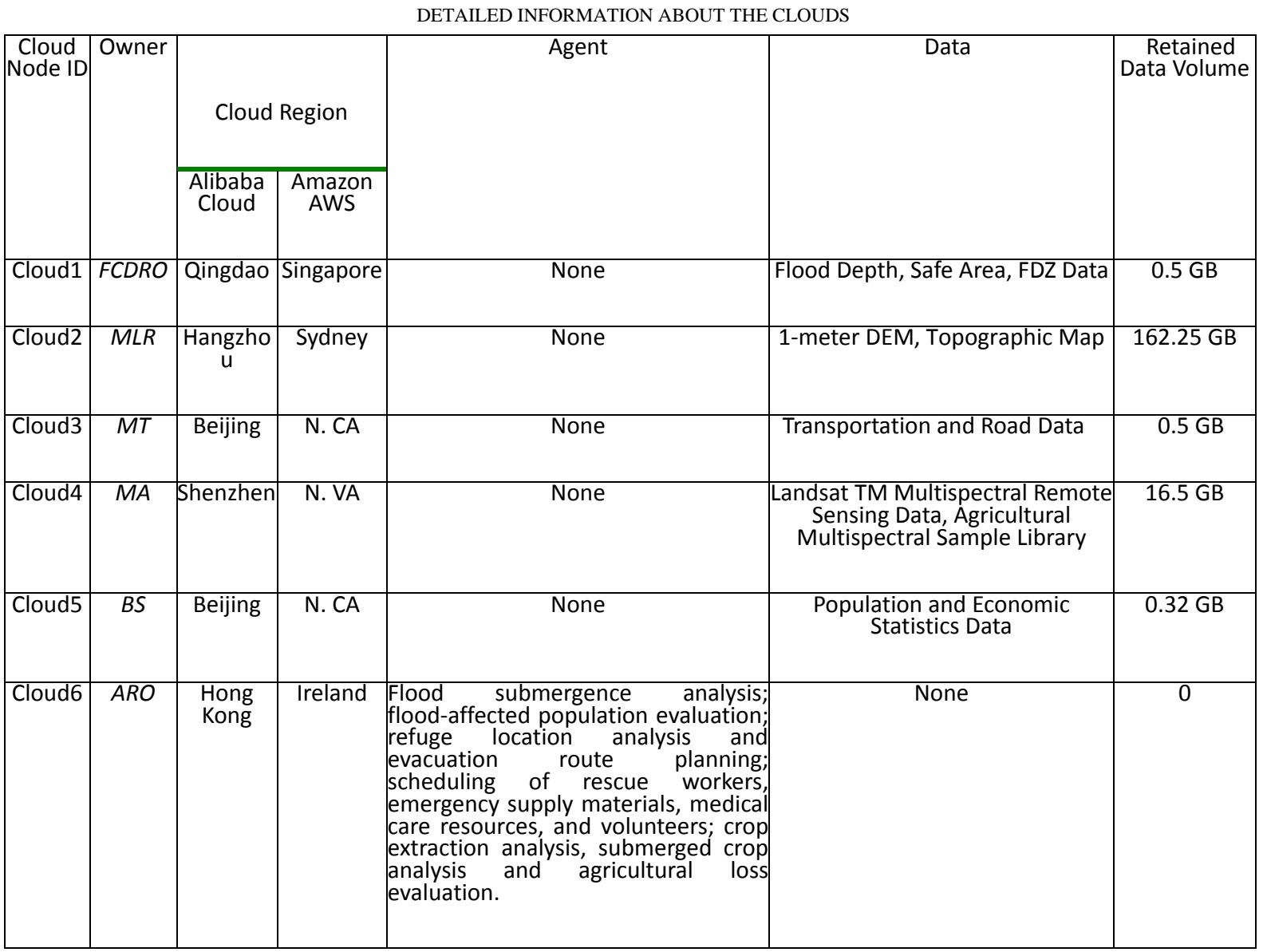

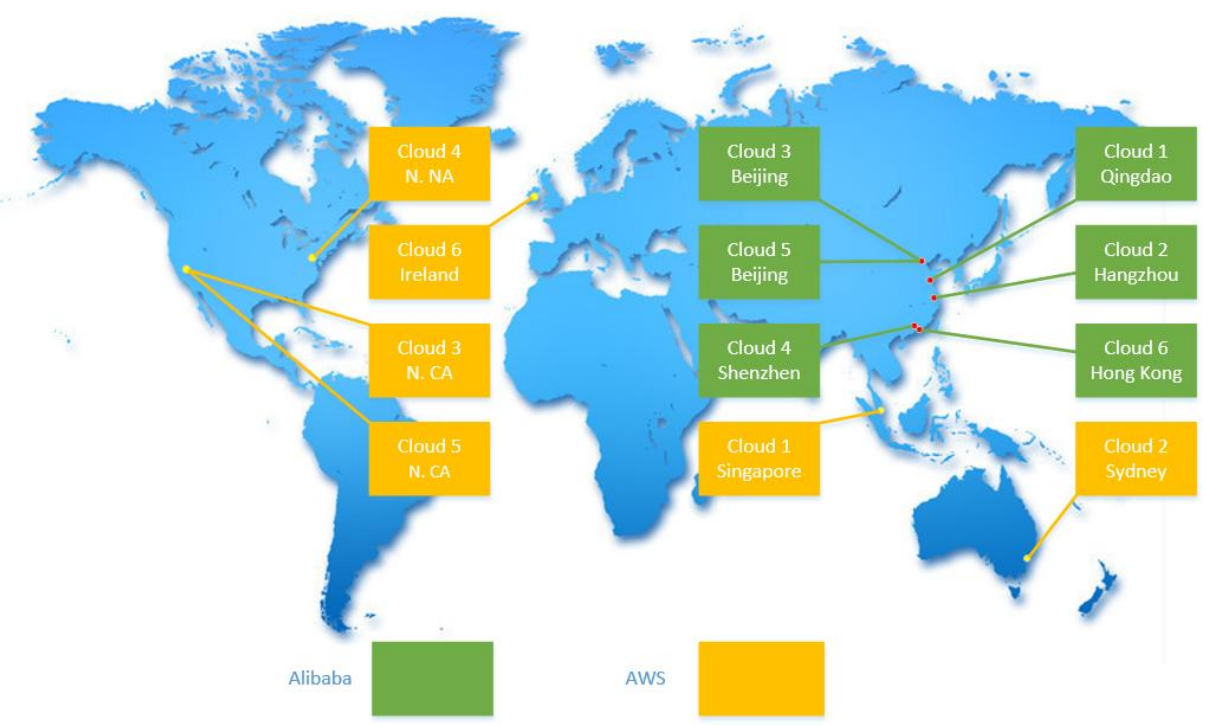

Fig. 6. Distributions of the Cloud nodes in the AWS and Alibaba Cloud 
In total, six Windows Server 2008 R2 Cloud VMs were created from the free Cloud instance image. The AaaS infrastructure, Geoserver 2.7, Openlayers 3.0, Grass GIS 6.44 and $52^{\circ}$ North WPS, an open-source software for managing and publishing WPS, were installed in the image so that every Cloud VM had the appropriate environment for Agent migration and geoprocessing. In the system, Geoserver and Openlayers are used to publish and display the geospatial data and analysis results, and a Microsoft Bing map is used as the background map. $52^{\circ}$ North WPS is used to register and transform agents into the WPS. Geographic analysis programs associated with the Flood Response Model were developed using Grass GIS 6.44.

In this research, it is not practical to develop self-contained agents. Agents rely on three dependencies: AaaS infrastructure, geoprocessing libraries (e.g., Grass GIS) and the geospatial server (e.g., Geoserver and $52^{\circ}$ North WPS). One major reason is that agents need to move between different Cloud nodes and convert into WPS service via the AaaS infrastructure. Thus, agents cannot contain the AaaS infrastructure. The infrastructure and geoprocessing libraries must be installed in every Cloud nodes. Agents will perform geoprocessing based on the geoprocessing libraries. Moreover, the geospatial server and $52^{\circ}$ North WPS are also required to publish the produced results and the Agent-generated WPS services. Therefore, self-contained agents are not used in this work.

Although it is challenging to build completely self-contained agents currently, it is feasible to configure all the dependencies in multiple Cloud regions automatically in advance via Cloud services. For example, a Cloud image that has dependencies can be created and shared in all Cloud regions. Then, an agent can move to the Cloud nodes in all the Cloud regions and execute. This process can be handled automatically. Therefore, it is much faster and more convenient to make an agent move in the Cloud rather than with the physical machines. In the experiment, during execution, the application will ensure that dependencies are available in the Cloud node by searching the records before giving the agents migration instructions. The records are hosted in every Cloud node that has the three dependencies. As a result, before the agents migrate, all Cloud nodes with those dependencies are known by all agents.

The prototype system has been deployed in both the Alibaba Cloud and AWS Cloud for our experimental tests. However, only the Alibaba Cloud system will be continuously available for public testing and use after our experiments. The prototype system can be used and tested online at http://121.42.15.232:7070/SetMethod, which is also given in Fig. 7.

After a request is submitted by pressing the "START ANALYSIS" button in the portal, a flood response analysis is executed. The service aggregation produces real-time results for a rapid flood response and displays the results. Fig. 7(a) shows the results for the submerged crops, whose areal extent is determined according to the submerged area and the crop area. Fig. 7 (b) shows the results for the evacuation routes and refuge locations, which assist the DERO in evacuating the flood-affected population. Additionally, the users can query food and fresh water requirement levels by clicking the refuge polygon. Similarly, users can also query the 
medical care, disaster and emergency relief resources and volunteer requirement information in a specific refuge, as shown in Fig. 7(c-e).

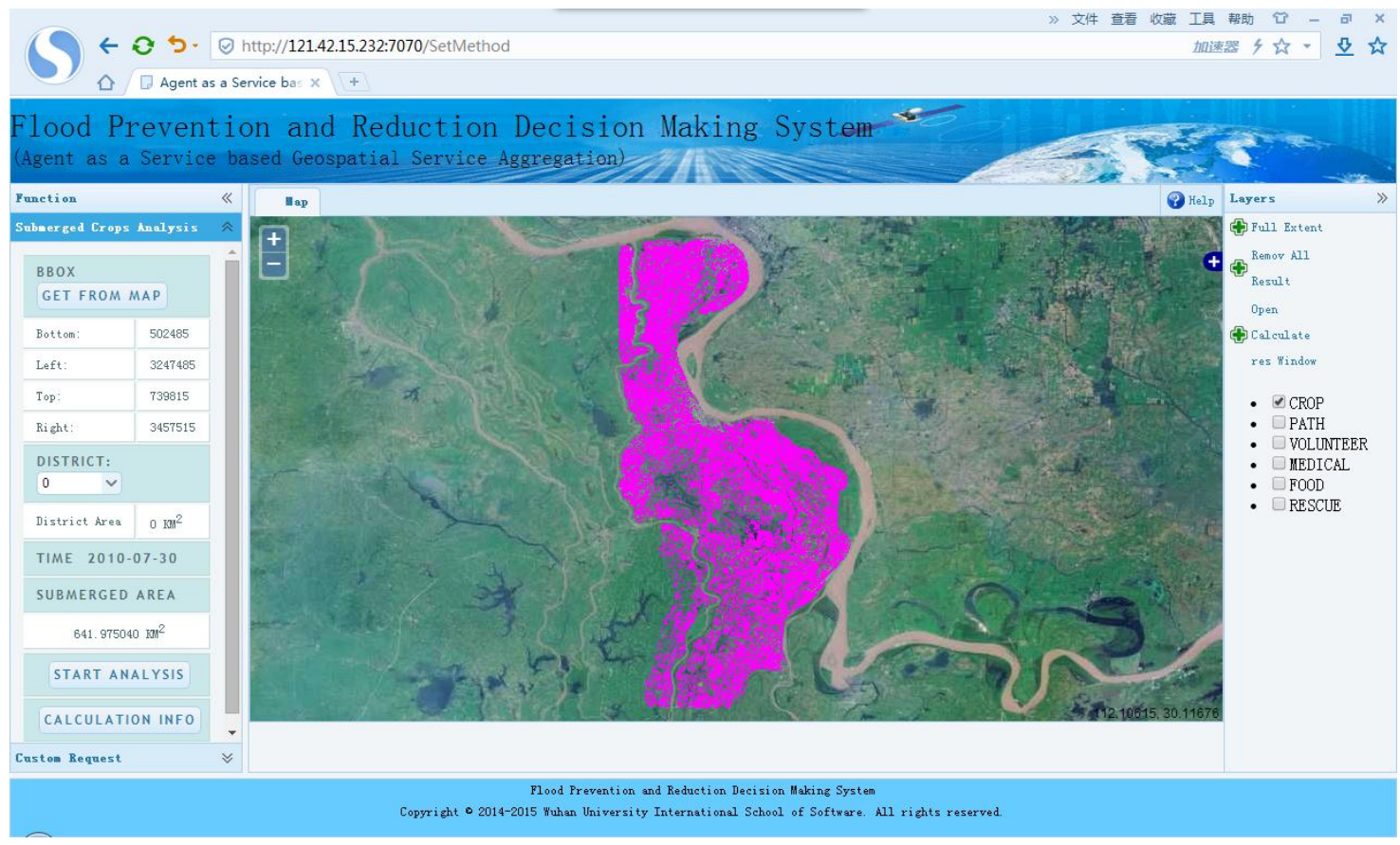

(a) Submerged crops

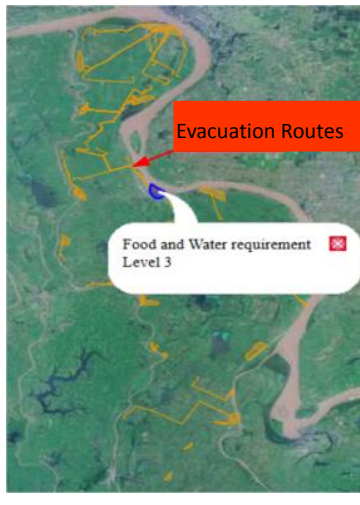

(b) Food and fresh water

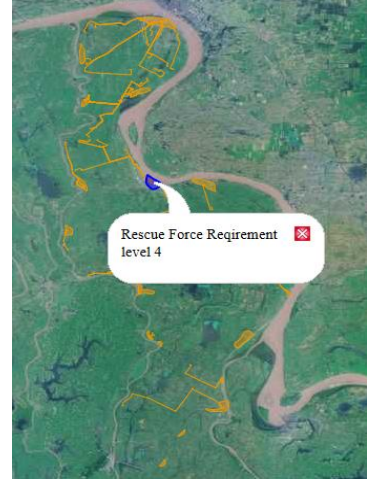

(c) Rescue and relief worker requirements

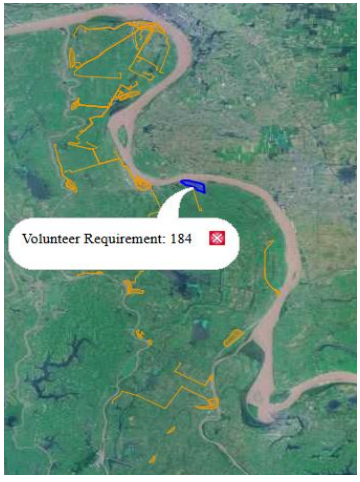

(d) Volunteer requirements

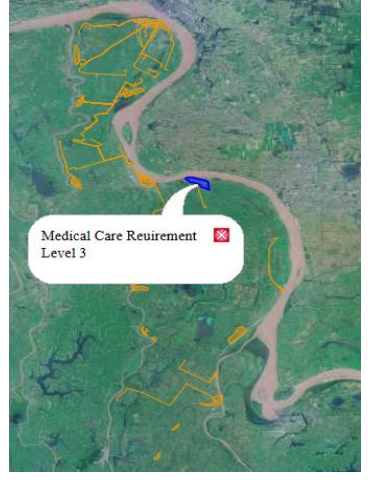

(d) Medicine requirements

Fig. 7 The prototype system

To demonstrate the AaaS-based method addresses the challenges associated with geospatial services aggregation, no original WPS services were deployed in the distributed Cloud nodes. All WPS services are generated by agents based on the AaaS. Consequently, the WPS can migrate wherever the process is required, which is distinctly different from traditional SOA-based methods. The environment configuration and execution result of the prototype system demonstrate that the challenges associated with separately hosted services and data can be solved by the AaaS-based method. The Agent-generated WPS will move to and remain in the target nodes, working independently to enrich the geospatial services of the target nodes in the distributed environment. Additionally, all WPS services originate from 
agents that were registered by the users via the AaaS infrastructure without any use of geospatial service knowledge. Therefore, domain experts are not required to have geospatial service knowledge, and these experts can focus on domain problems and algorithms. All of the geospatial service-related works are performed by the AaaS infrastructure, therefore, the AaaS-based method can help promote the participation of domain experts and authorities, assisting domain experts in solving interdisciplinary problems. Additionally, unlike the Cloudand Agent-based methods (Tan, 2015), in the AaaS-based method, all communication between agents is conducted in a standard way (via the OGC Web Services). This communication process is more beneficial for the implementation of complex service-aggregating systems.

\subsection{Performance Issues}

To demonstrate that AaaS-based geospatial service aggregation is more efficient and robust than the traditional SOA method, three comparisons are conducted.

(1) Descriptions of comparative approaches

The system performance and robustness evaluations are based on comparative tests between our proposed approach (Approach 3) and two other approaches (Approaches 1 \& 2).

Approach 1: SOA-based service aggregation on physical machines. This approach uses OGC Web Services to conduct the service aggregation. All the requisite WPS services are built on one physical machine, and required spatial data are acquired through WCS and WFS from the data machines. All machines are in identical local area networks (LANs) with bandwidths of $1000 \mathrm{Mbps}$, and NetLimiter 3.0 was used to set the data transfer rate (DTR) to specific values to simulate a distributed environment network.

Approach 2: SOA-based service aggregation in the Cloud. This approach is identical to Approach 1, but run in the Cloud. All requisite WPS services are built in one Cloud VM, and the required spatial data are acquired through WCS and WFS from the data nodes, which are connected via the Internet.

Approach 3: AaaS-based method. The configurations of the machines and Cloud VMs in the tests are listed in Table 3. Additionally, we tested the methods in the Alibaba Cloud and Amazon AWS separately. In the experiments, NetLimiter 3.0 was used to set the Internet DTR of the Alibaba Cloud VMs to three different values (1.0, 5.0, and $10.0 \mathrm{Mbps}$ ) to simulate various network conditions. We did not limit the Amazon AWS network because the AWS Cloud nodes are connected to the global Internet, which is unstable when compared to domestic networks.

TABLE 3 


\begin{tabular}{|c|c|c|}
\hline Approach & Machine Configuration & $\begin{array}{l}\text { Deployment of Data, Services } \\
\text { and Agents }\end{array}$ \\
\hline 1 & $\begin{array}{l}\text { Six physical machines operating with Windows, dual-core } \\
\text { CPUs with } 2.20 \mathrm{GHz}, 8 \mathrm{~GB} \text { of RAM, 1-TB disks and LAN } \\
\text { network with bandwidths of } 1000 \mathrm{Mbps}\end{array}$ & $\begin{array}{l}\text { WPS services in one machine } \\
\text { and spatial data in five separate } \\
\text { machines }\end{array}$ \\
\hline \multirow[t]{2}{*}{2} & $\begin{array}{l}\text { Six Alibaba Cloud Windows VMs, each with four VCPUs with } \\
2.6 \mathrm{GHz}, 8 \mathrm{~GB} \text { of RAM, a 150-GB disk and DTR of } 10 \mathrm{Mbps}\end{array}$ & \multirow[t]{2}{*}{$\begin{array}{l}\text { WPS services in Cloud } 6 \text { and } \\
\text { spatial data in the other Cloud } \\
\text { nodes }\end{array}$} \\
\hline & $\begin{array}{l}\text { Six c4.xlarge AWS Windows VMs, each with four VCPUs with } \\
2.80 \mathrm{GHz}, 7.5 \mathrm{~GB} \text { of RAM, 140-GB disks and moderate speed } \\
\text { networks }\end{array}$ & \\
\hline \multirow[t]{2}{*}{3} & $\begin{array}{l}\text { Six Alibaba Cloud Windows VMs, each with four VCPUs with } \\
2.6 \mathrm{GHz}, 8 \mathrm{~GB} \text { of RAM, 150-GB disks and DTR of } 10 \mathrm{Mbps}\end{array}$ & \multirow[t]{2}{*}{ As shown in Table 2} \\
\hline & $\begin{array}{l}\text { Six c4.xlarge AWS Windows VMs, each with four VCPUs with } \\
2.80 \mathrm{GHz}, 7.5 \mathrm{~GB} \text { of RAM, 140-GB disks and moderate speed } \\
\text { networks }\end{array}$ & \\
\hline
\end{tabular}

(2) Performance comparison

To evaluate its performance and confirm that our approach is more efficient than the traditional SOA-based method, comparisons were conducted under different conditions. Fig. 8 presents the test results from the Alibaba Cloud, illustrating the execution times using the three approaches under different network DTRs and for different numbers of requests.

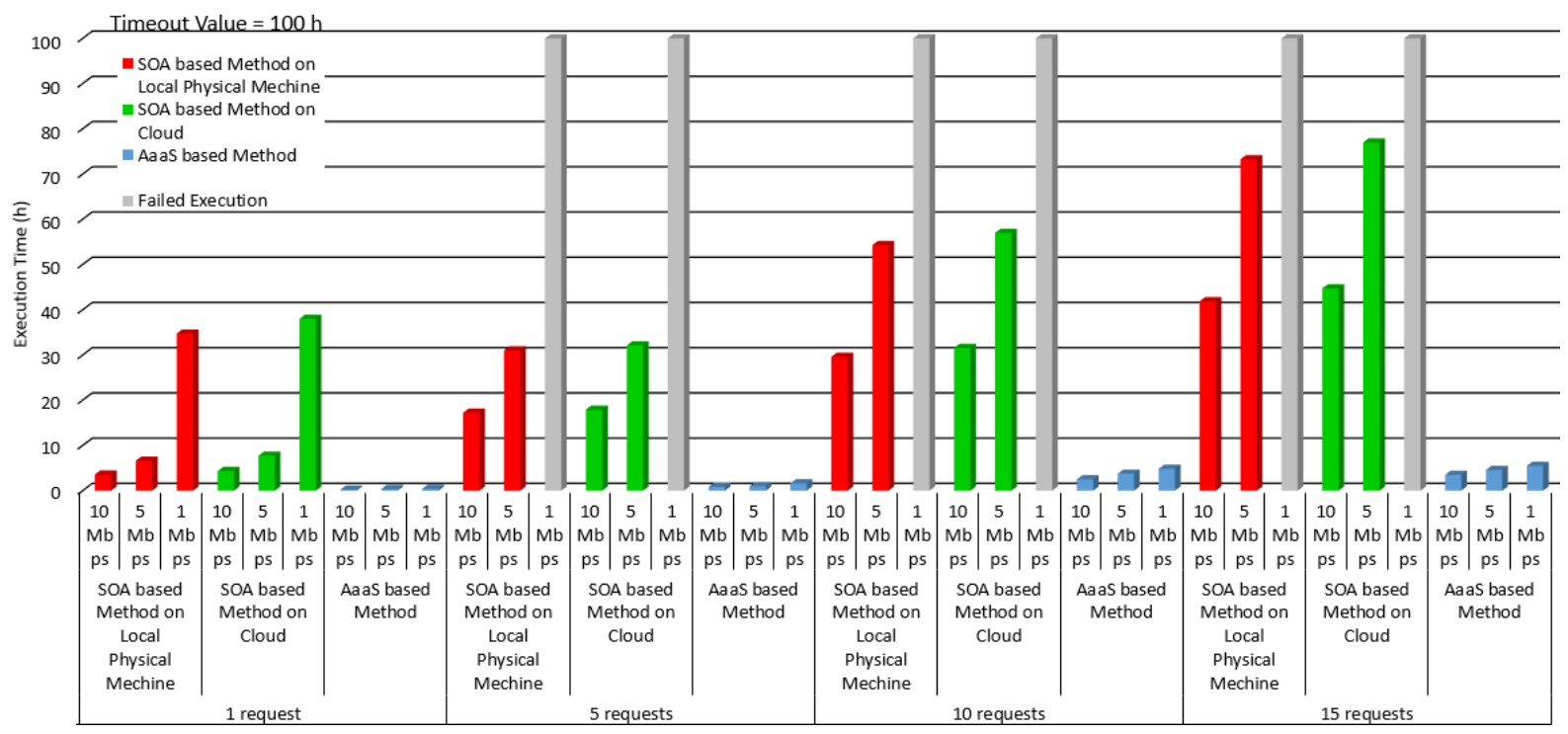

Fig. 8 Test results from the Alibaba Cloud

To evaluate the effects of the network condition and number of concurrent requests on the performance, we tested three approaches using different DTRs and numbers of requests in the Alibaba Cloud (Fig. 8). For approaches with identical DTRs, the AaaS-based method is better than the two SOA-based methods. For example, when the DTR is $10 \mathrm{Mbps}$ with only one request, the AaaS-based method requires approximately $0.24 \mathrm{~h}$ to finish the execution. However, the two SOA-based methods require almost $4 \mathrm{~h}$. When the DTR was set to $1 \mathrm{Mbps}$, 
the SOA-based methods require more than $30 \mathrm{~h}$ to finish the task. By contrast, the AaaS-based method takes only $0.43 \mathrm{~h}$. The experiments also show that the differences in the execution time between the AaaS-based method and SOA-based methods increase when the DTR decreases and the concurrent requests increase. For example, when the DTR is $10 \mathrm{Mbps}$ with only one request, the execution time of the SOA-based method is approximately 10 times larger than the execution time of the AaaS-based method. When the network speed decreases to $5 \mathrm{Mbps}$ and the number of concurrent requests increases to 15 , this difference increases to 12.5 -fold. When the DTR decreases to $1 \mathrm{Mbps}$ with more than five concurrent requests, the SOA-based method requires more than 100 hours and timeout failure occurs; however, the AaaS-based method requires only approximately 5 hours, even for 15 concurrent requests. These experimental results show that our AaaS-based method performs better than the two SOA-based approaches for multiple requests and poor network conditions.

The tests in the Amazon AWS Cloud also show the superiority of the AaaS-based method. Because the DTR of an international network is usually worse than that of a domestic network, we used six c4.xlarge instances with a moderate network speed. The network DTR is unstable from day to night and varies from $0.1 \mathrm{Mbps} \sim 5 \mathrm{Mbps}$. The request timeout value was set to $100 \mathrm{~h}$. The performance test results of Approach 2 and 3 are shown in Fig. 9.

As shown in Fig. 9, using the AaaS-based method in the AWS Cloud, one request requires only $0.28 \mathrm{~h}$. However, using the SOA-based method, 43 hours were required, which is an execution time that is almost 153 times longer than the execution time of the AaaS-based method. For multiple requests, the new method spent $0.72 \mathrm{~h}, 3.5 \mathrm{~h}$ and $5.26 \mathrm{~h}$ for 5,10 and 15 requests, respectively. However, all of these requests failed because of timeouts using the SOA-based method in the AWS Cloud, indicating that for more than five concurrent requests, the SOA-based method requires more than $100 \mathrm{~h}$ to produce a decision, which is not suitable for emergency response events such as flooding and earthquakes. Therefore, the performance of the AaaS-based service aggregation is far better than that of the traditional SOA-based method, notably for low efficiencies and an unstable network.

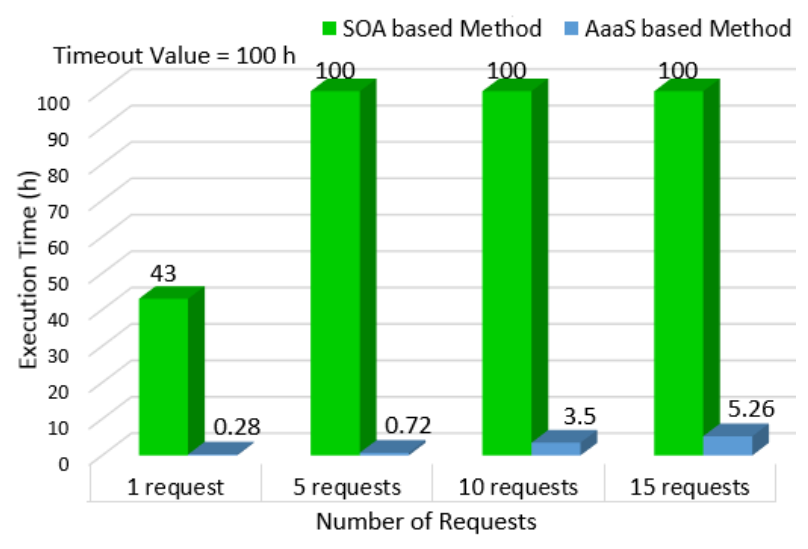

Fig. 9 Test results from the Amazon AWS Cloud 
(3) Data Transfer Comparison

To understand the results of the performance comparison, the data transfer volumes of the three approaches are considered in Fig. 10.

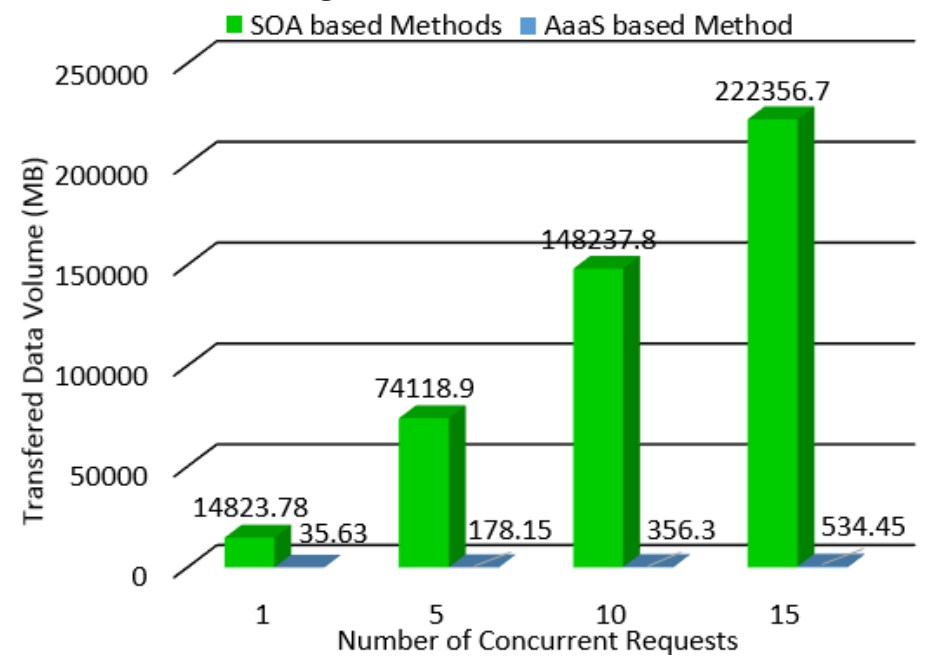

Fig. 10 Volume of data transfer

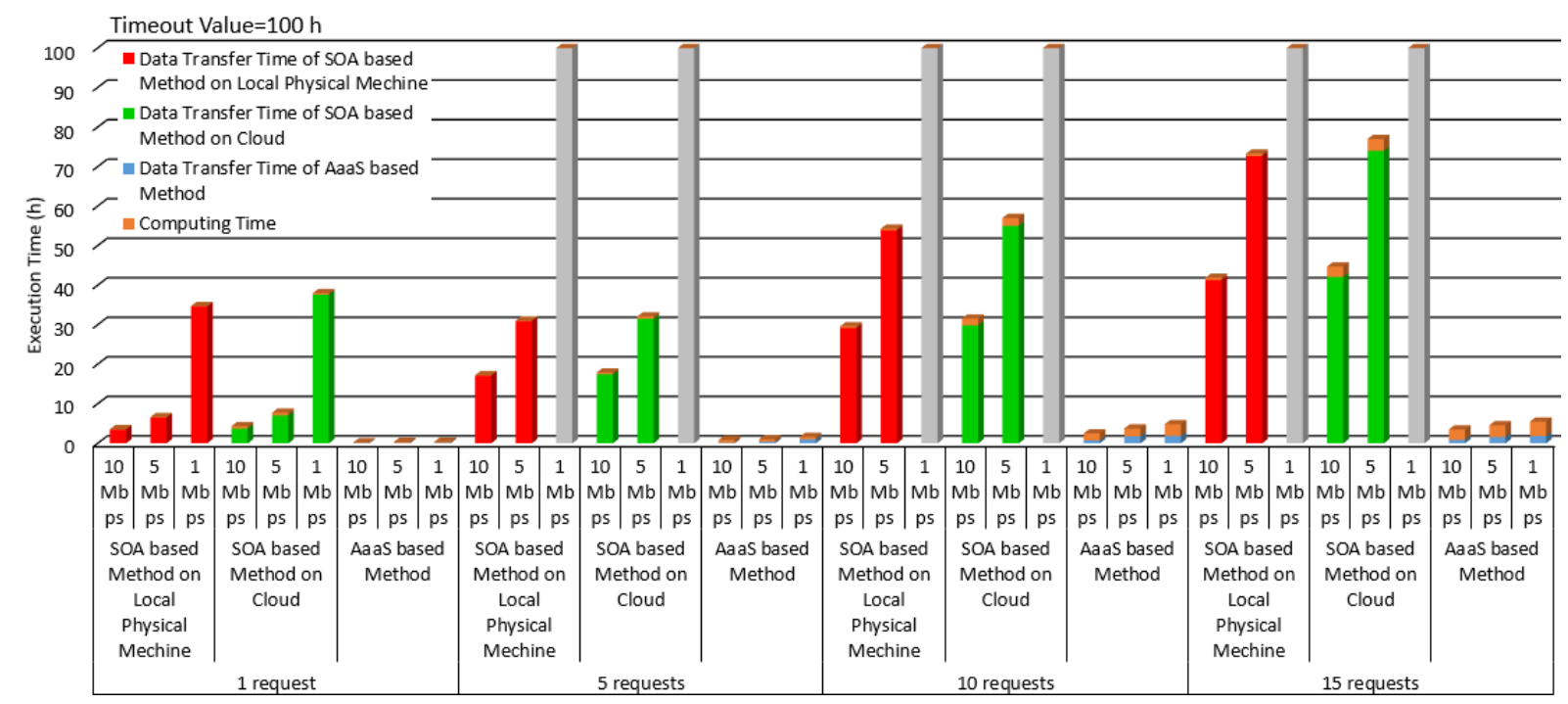

Fig. 11 Data transfer time analysis

Fig. 11 shows that both SOA-based approaches transfer all the spatial data online through geospatial data services (e.g., WFS, WCS). For one request, the SOA-based methods require the transfer of approximately $14.8 \mathrm{~GB}$ of data over the Internet. When the number of concurrent requests is 15 , the total volume of data transfer is $222.4 \mathrm{~GB}$. By contrast, the AaaS-based method only transfers a small volume of spatial data (e.g., GML data or single-color raster data) and mobile agents. As shown in Fig. 10, the AaaS-based method only requires the transfer of $0.5 \mathrm{~GB}$ of data, even for 15 concurrent requests. Fig. 11 shows the time required for data transfer and computation for methods with different concurrent requests and upon various network DTRs. When the SOA-based method occurs on a physical machine with a $1 \mathrm{Mbps}$ DTR, the data transfer time is $34.6 \mathrm{~h}$ for a single request, slightly better than that produced using SOA-based methods in the Alibaba Cloud. With the 
AaaS-based method, the data transfer time is only approximately $0.13 \mathrm{~h}$, which is much shorter than that of the SOA-based methods. In addition, when more than five concurrent requests occur and the DTR is $1 \mathrm{Mbps}$, both SOA-based methods require execution time that are longer than the timeout value (i.e., $100 \mathrm{~h}$ ) to transfer the data, causing request failure. However, using the AaaS-based method, the data transfer time is only approximately $1.85 \mathrm{~h}$, even for 15 concurrent requests and a DTR of $1 \mathrm{Mbps}$. By utilizing the computing capabilities of agents, the AaaS-based method effectively reduces the data transfer volume and data transfer time.

Although the service output data only consist of some small-sized vector data and single-layer raster data in this case, we must consider cases where service output data sets, as inputs in the next service, are very large (e.g., a large hyperspectral image, high resolution image or large GML vector data set). In such cases, agents will migrate to large data sets to reduce the data transfer time. When a service requires more than one input and when all output data sets of previous services are large and hosted in different nodes, according to Case 2 presented in Section 3.3, agents will migrate to the node with the largest output data set, and the output data in other nodes will be transferred to the agents. Although the performance level may not be as good as that of the flood response scenario, the data transfer time will still be shorter than that of SOA-based methods.

\section{(4) Agent behavior performance}

To analyze that degree to which agent behaviors affect service aggregations, we obtained the execution times associated with three major agent behaviors: agent search, migration and registration. During flood response geospatial service aggregations, 5 agents (i.e., flood submergence analysis, refuge location analysis, evacuation route planning, crop extraction analysis, submerged crop analysis and agricultural loss evaluation) migrated to the data, and the other agents did not migrate. We determined the average execution times required by the three major behaviors of the five agents that migrated to the data, as shown in Fig. 12.

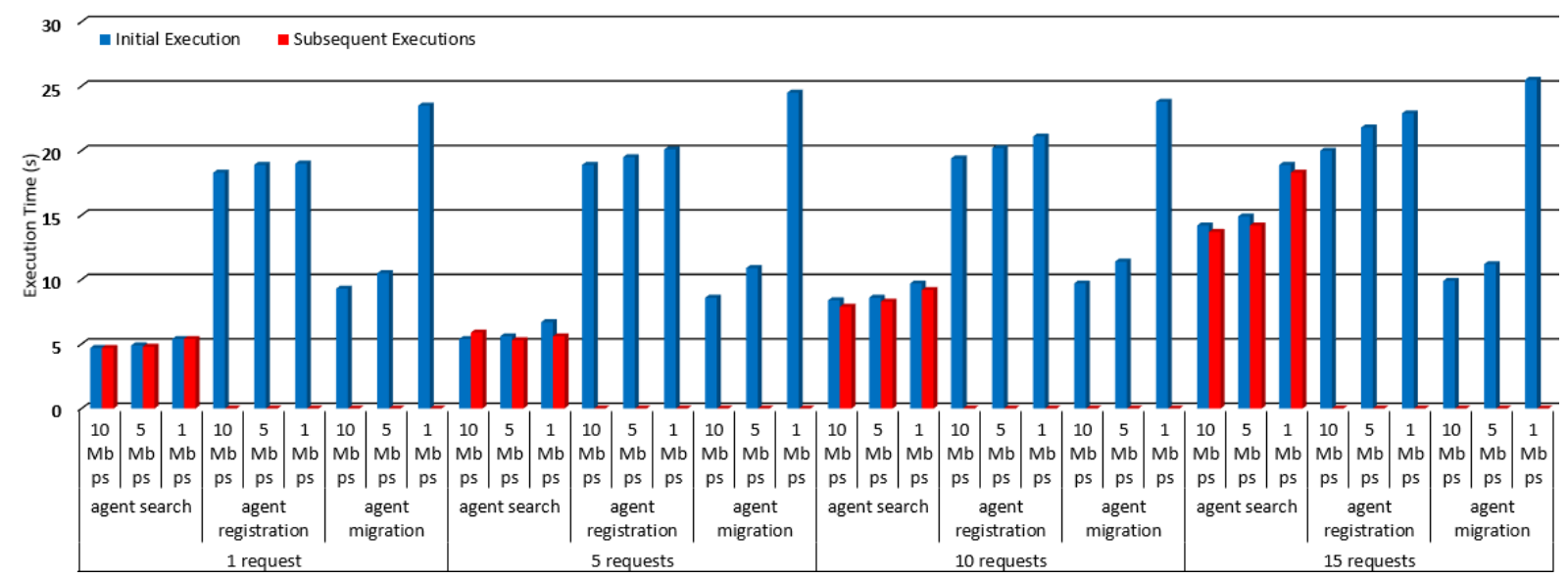

Fig. 12 Average Agent Behavior Time in the Alibaba Cloud

The agent search period increases with the number of concurrent requests, as concurrent requests require more search operations in the CSW. In addition, agent search periods are also affected by catalog data retained in the CSW, as more data require longer search times. 
The execution time for agent migration and registration did not increase considerably with the number of concurrent requests during the initial execution. Although the agent detected multiple identical migration instructions (same agent id and same target node) from concurrent requests, the agent only migrated once to avoid duplicate behavior. In the subsequent executions, an agent registration and migration period did not occur because after the initial execution phase, all agents that needed to migrate had migrated to the target nodes. Thus, the agents no longer needed to migrate and register. However, when requisite data are changed (this did not occur in the flood response scenario), an agent may need to migrate and register, as in the initial execution phase.

From Fig. 12, we can conclude that the execution times of agent behaviors can be neglected in this case, even though it is an initial execution, as the execution times of the three major agent behaviors are no more than 30 seconds, which is far less than the data transfer time and geocomputing time, even when there are 15 concurrent requests. However, when there is a large agent that must be migrated to a larger data set, the execution time of agent migration cannot be neglected during the initial execution stage; however, it will still be less than the time needed to move larger data to the service. No matter how large the agent, if the agent only uses the same data sets or data sets retained in the same nodes after initial execution, the execution times of agent behaviors can also be neglected, as the agent has already migrated to the data set and registered during initial execution. As a result, agent behaviors can help optimize service aggregation efficiency levels, which is especially influential when many users engage in service aggregation repeatedly or concurrently.

\subsection{Robustness Analysis}

To show that our method is more robust than the traditional SOA-based method, we turned off the geospatial service server, Cloud 6, in this prototype system during the execution of the composite service; however, the AaaS-based method still executed successfully. This distinction between our AaaS-based method and the traditional SOA-based method results from the fact that all tasks in the SOA-based method are processed in the service server during the execution of the composite service, as shown in Fig. 13(a). When the service server collapses, the composite service will fail. In the AaaS-based method, as shown in Fig. 13(b), all agents are migrated to data nodes as soon as the composite service begins to run. Even if the service server becomes invalid, the composite service can still execute and complete the tasks successfully. This test shows that the AaaS-based method can enhance the decentralized capability of the service aggregation system and offer a more robust composite service. Furthermore, as we have previously mentioned, the agents move to and remain at target nodes, creating duplicates of the agents and WPS services. Therefore, although Cloud 6 fails before the agents move to other nodes, the service will still execute successfully using the duplicates of required agents at other nodes. 


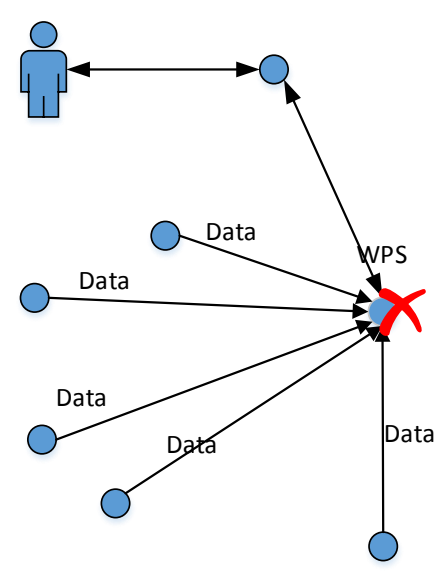

(a) Failed Execution

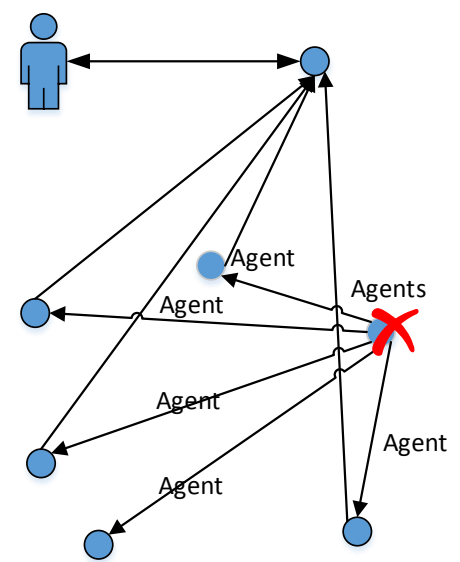

(b) Successful Execution

Fig. 13 Robustness Analysis

By utilizing the capability of Cloud computing, when a VM breaks down, the VM in the Cloud can be replaced by a newly launched VM with an identical configuration. For example, Approach 2, as described in Table 3, can launch a new geospatial service server. This capability can reduce the robustness issue associated with SOA-based service aggregation to a certain extent. However, launching a new VM will take several minutes and increase the execution time of SOA-based service aggregation. By contrast, the agent servers of the AaaS-based method, too, can launch a new VM to replace the invalid VM; however, the process does not affect the execution of the AaaS-based composite service. If the service server becomes invalid, Approach 1 described in Table 3 must generally be recovered manually, hence, displaying poor robustness. In addition, with Approach 1 and 2, one can configure manually duplicated Cloud-based servers or physical machine servers in advance to avoid single server failure. However, when the services are provided by organizations all over the world, it is generally difficult to ask all the providers to build duplicates of their servers, let alone to build all the duplicated services in the involved data nodes, as the AaaS-based method does.

\section{Discussion}

According to the experiments, the proposed methodology has satisfactory merit. However, some aspects, such as generalization, scalability, high-performance requirements, security, etc., need to be better considered in the future. More focus should be placed on these problems to make the AaaS-based geospatial service aggregation method more valuable in open distributed systems.

\subsection{Generalization Expectations}

Generalization requirements are also important for the proposed method when generalizing 
the proposed method to geospatial applications other than flood response. In the method described in this paper, all geospatial data communications of agents are based on the OGC Web Services (i.e., WFS, WCS, WPS), and all agents can be invoked as WPS services, accept WFS and WCS as inputs, and be found via the CSW. Therefore, the AaaS-based method can be used to process geospatial data in a standardized manner. This standardized approach makes the technique generalizable to other geospatial applications, such as traditional SOA-based geospatial services. On the other hand, all Agent-related fundamental functions (i.e., WPS generation, agent cloning, migration, and registration) are managed by agent environments and are transparent to users. Users do not need to consider internal mechanisms of agent environments and only need to configure the AaaS infrastructure because agents can migrate across different Clouds through the AaaS infrastructure, and the AaaS infrastructure contains all the aforementioned Agent-related functions. Hence, users only need to focus on WPS services, which can be found via the CSW and which can be invoked via http requests. Treating all agents as standard OGC WPSs can also help generalize this method.

However, to achieve better generalization capabilities, more research efforts are needed. For example, when determining whether to move data or agents, which target node an agent should migrate to, and which agent should be selected, the proposed method must consider more factors, which include network conditions (e.g., network speed, stability, security, etc.), the performances of data service servers (WCS, WFS, and WMS), the performances and accuracies of agents with the same functions, and other factors encompassed by the quality of service (QoS) concept. Such avenues of research will prove challenging but are important.

\subsection{Scalability and High-performance Requirements}

The experiments based on the performance comparison show that the proposed AaaS-based method meets the goal of this paper directly. It enables the migration of services to a target node for finishing a task, allowing separately hosted services and data to function at the same node in the decision-making system, avoiding the transfer of large volumes of spatial data over the network and strengthening decentralization of the geospatial service aggregation application. In comparison to the traditional SOA-based method, our AaaS-based method has demonstrated much better performance and robustness. However, its performance is not promising in some situations. For example, the execution time is approximately $5 \mathrm{~h}$ when there are 15 concurrent requests, indicating that it may not meet some decision-making requirements. Moreover, under the circumstance of generalizing the AaaS-based method for use in other applications that require many concurrent requests (e.g., applications for public users), many agents will try to migrate to and execute at the same host node. Hence, the scalability and performance of the proposed approach require further improvements. In future work, we will integrate parallel and load-balanced geospatial processing into the proposed AaaS-based method. Additionally, a more intelligent AaaS-based method will potentially be developed to avoid many agents migrating to the same host node at the same time. 


\subsection{Security Challenges}

The purpose of the AaaS-based method is to optimize a composite geospatial service in a secure and trusted distributed systems context, e.g., in flood response systems. In this environment, all agent developers in the system are authenticated. As a result, all agents can be identified and tracked, ensuring system security. However, if the method is going to be used in open distributed systems in the future for various applications, more measures should be adopted to ensure system security. First, digital authentication technology (e.g., trust anchors and other best practices) will be considered to ensure agent security. Furthermore, to protect the service at another level, additional countermeasures such as anti-virus software and other monitoring approaches can be utilized to ensure that malicious behaviors can be detected and eliminated with a high degree of confidence. In addition, by utilizing the Cloud platform, an agent moves to a VM in the Cloud, although the agent is malicious, it can only affect the target VM in which the agent executes. However, the malicious agent cannot affect other VMs or the Cloud platforms because there are security policies in the Cloud platforms, such as AWS, Azure, Alibaba Cloud, etc. Hence, to enhance the security level of the system, agents of different trust levels should migrate to different VMs. Finally, new usage mode or commercial mode should be designed to ensure better security. For example, the agent providers that build the agents launch their own VMs at the target Cloud regions. The agent providers can charge users for those agents, thus preventing service providers from building malicious agents to hurt them or the users. We believe that all these measures can help to improve the security of the AaaS-based method in open distributed systems.

\section{Conclusions}

We proposed an AaaS-based service aggregation method to address problems associated with constructing and executing a composite geospatial service for flood response. These problems include the low transfer efficiency of large volumes of spatial data, service server failure, and the difficulty related to encouraging domain experts to participate. This study is of great importance and necessity because the volumes, types and applications of geospatial data (e.g., EOS data and Sensor Web data) increase continuously; the scales of networks continue to expand considerably; and more interdisciplinary issues must be addressed. Analyses of rapid responses to a simulated flood in the Yangtze River Basin have demonstrated the feasibility, efficiency, effectiveness and robustness of the proposed method and indicated that the method is able to perform geospatial tasks better during emergencies such as floods. Given the capacity of AaaS in a Cloud, this method can avoid large volume transfers of geospatial data and achieve acceptable performance and robustness (even for multiple concurrent requests under various network conditions). This capacity will be critical for spatially distributed big data processing. This method can also prevent failures in composite service execution when the service server becomes invalid. This decentralization capacity is important when the network is large and unstable. Migration 
of the Agent-generated WPS can enrich the service resources of nodes in a distributed environment. Furthermore, this method encapsulates the agent in the WPS service; therefore, domain experts without geospatial service expertise can easily use it. Hence, this method allows experts from different domains to collaborate and develop decisions. This collaboration is key for addressing interdisciplinary issues such as rapid response to natural disasters and environmental risks (e.g., floods, earthquakes, typhoons, and pollutions).

Future research efforts will enhance the robustness of complex AaaS-based service aggregations. More efforts must be made to exploit the properties of Cloud computing to improve the reliability and security of the AaaS method. The QoS of geospatial services in the Cloud environment must also be studied. High-performance computing techniques can be used to optimize the efficiencies of geospatial service aggregation methods, particularly when Spatial Big Data (SBD) are involved. Furthermore, the cost efficiency model of Cloud-based geospatial services will be studied in the future.

\section{Acknowledgments}

We thank Prof. Xiaohui Cui and Prof. Frederick Sheldon for their detailed comments, which helped to improve the quality of the paper, and Julia Di of Columbia University for proofreading this paper. The authors also thank the editors and the reviewers for their outstanding comments and suggestions, which greatly helped to improve the technical quality of the manuscript. This study was supported in part by NSFC (No. 51277167 and 41371371), the Fundamental Research Funds for the Central Universities (Self-adaptive Measure Generalization based Spatio-temporal Association Rules Mining for Abnormal Event Discovery). Authors affiliated with George Mason University were also supported in part by a U.S. National Science Foundation grant (ICER-1440294, PI: Dr. Liping Di). The work conducted by Dr. Huang was supported by the Fundamental Research Funds for the Central Universities (Grant No. ZYGX2015J111).

\section{References}

Alongi, D. M., 2008. Mangrove forests: resilience, protection from tsunamis, and responses to global climate change. Estuarine Coastal \& Shelf Science, 76(1), 1-13.

Arpinar, I.B., Zhang, Ruoyan., Aleman, M.B., Maduko, A., 2005. Ontology driven Web services composition platform. Information Systemsand e-Business Management. 3(2),175-199.

Bianconi, R., Galmarini, S., \& Bellasio, R., 2004. Web-based system for decision support in case of emergency: ensemble modelling of long-range atmospheric dispersion of radionuclides. Environmental Modelling \& Software, 19(4), 401-411.

Brown, D.G., Riolo, R., Robinson, D.T., North, M., Rand, W., 2005. Spatial process and data models: Toward integration of agent-based models and GIS. Journal of Geographical Systems. 7(1),25-47.

Brown, D.G., Xie, Yichun., 2006. Spatial agent - based modelling. International Journal of Geographical Information Science. 20(9), 941-943.

Bithell, M., Brasington, J., 2009. Coupling agent-based models of subsistence farming with individual-based forest models and dynamic models of water distribution. Environmental Modelling \& Software. 24(2), 173-190. 
Bitterman, T., Calyam, P., Berryman, A., Hudak, D., Li, L, Chalker, D., Gordon, S., Zhang, D, Cai, D., 2014. Simulation as a service (SMaaS): a cloud-based framework to support the educational use of scientific software. International Journal of Cloud Computing. 3(2), 177-190.

Ben-Yehuda, O.A., Ben-Yehuda, M., Schuster, A, Dan, T., 2014. The rise of RaaS: the resource-as-a-service cloud. Communications of the ACM. 57(7): 76-84.

Bræk, R., Melby, G., 2005. Model-Driven Service Engineering. Model-Driven Software Development. ISBN-10 3-540-25613-X Springer Verlag, 385-401.

Castronova, A.M., Goodall, J. L., Elag, M.M, 2013. Models as web services using the open geospatial consortium (ogc) web processing service (wps) standard. Environmental Modelling \& Software. 41, 72-83.

Chen, N., Di, L., Yu, G., Gong, J., Wei Y., 2009. Use of ebRIM-based CSW with sensor observation services for registry and discovery of remote-sensing observations. Computers \& Geosciences. 35(2), 360-372.

Chen, N., Di, L., Yu, G., Gong, J, 2010. Geo-processing workflow driven wildfire hot pixel detection under sensor web environment. Computers \& Geosciences. 36(3), 362-372.

Chen, N., Di, L., Yu, G., Gong, J, 2010. Geo-processing workflow driven wildfire hot pixel detection under sensor web environment. Computers \& Geosciences.36(3), 362-372.

Chen, A., Di, L., Wei, Y., Bai, Y., Liu Y.B.Y,, 2009. Use of grid computing for modeling virtual geospatial products. International Journal of Geographical Information Science. 23(5), 581-602.

Christensen, A.F., Lucchi, R., Lutz, M., Ostlander, N., 2009. Service chaining architectures for applications implementing distributed geographic information processing. International Journal of Geographical Information Science. 23(5), 561-580.

Chen, Z., Chen, N., Yang, C., Di, L., 2012. Cloud Computing Enabled Web Processing Service for Earth Observation Data Processing. IEEE Journal of Selected Topics in Applied Earth Observations and Remote Sensing. 5(6), 1637-1649.

Duan, Y., 2012. Value modeling and calculation for everything as a service (XaaS) based on reuse[C], Software Engineering, Artificial Intelligence, Networking and Parallel \& Distributed Computing (SNPD). 2012 13th ACIS International Conference on. IEEE, $162-167$.

Dijkstra, J., Timmermans H. J. P., Jessurun A.J., 2001. A Multi-Agent Cellular Automata System for Visualising Simulated Pedestrian Activity. Theory and Practical Issues on Cellular Automata. 29-36.

Deng, M., P. Zhao, Y. Liu, A. Chen and L. Di (2004). The Development of a Prototype Geospatial Web Service System for Remote Sensing Data. The International Archives of Photogrammetry, Remote Sensing, and Spatial Information Sciences, http://www.isprs. org/congresses/istanbul2004/comm2/papers/126.pdf.

Deng, M., Di, L., 2008. GeoBrain Online Resources for Supporting College-Level Data-Intensive Geospatial Science and Engineering Education, Proc. IEEE Geoscience and Remote Sensing Symposium (IGARSS). IV-443-IV-446.

Deng, M., Di, L., 2009. Building an Online Learning and Research Environment to Enhance Use of Geospatial Data. International Journal of Spatial Data Infrastructures Research. 4, 77-95.

Deng, M., Di, L., 2010. Facilitating Data-intensive Research and Education in Earth Science - A Geospatial Web Service Approach. LAP LAMBERT Academic Publishing GmbH \& Co. KG, Saarbrücken, Germany, ISBN: 978-3-8383-9714-6.

Deng, M. \& Di, L. (2013). Building open environments to meet big data challenges in Earth sciences. Big Data Techniques and Technologies in Geoinformatics, H. Karimi, (Ed). Boca Raton, FL, USA: CRC Press, 2013, Ch. 4, pp. 67-88.

Deng M, Di L, Yu G, Yagci A, Peng C, Zhang B, and Shen D (2012). Building an on-demand web service system for global agricultural drought monitoring and forecasting. Proceedings of 2012 IEEE International Geoscience and Remote Sensing, Munich, Germany, July 22-27, 4pp.

Deng, M., Di, L., Han, W., Yagci, A., Peng, C., Heo, G., 2013. Web-service-based Monitoring and Analysis of Global Agricultural Drought. Photogrammetric Engineering \& Remote Sensing (PE\&RS). 79(10), 929-943.

Di, L., 2004. Distributed geospatial information services-architectures, standards, and research issues. The International Archives of Photogrammetry, Remote Sensing, and Spatial Information Sciences. 35(Part 2).

Di, L., 2005. A framework for developing Web-service-based intelligent geospatial knowledge systems. Geographic Information Sciences. 11(1), 24-28.

Di, L., Zhao, P., Yang, W., Yue, P., 2006. Ontology-driven automatic geospatial-processing modeling based on web-service chaining. In Proceedings of the sixth annual NASA earth science technology conference. 27-29.

Di, L., Zhao, P., Yang, W., Yue, P., 2006. Ontology-driven automatic geospatial-processing modeling based on web-service chaining. In Proceedings of the sixth annual NASA earth science technology conference. 27-29.

Di, L., Yang, W., Chen, A., Liu, Y., Wei, Y., Mehrotra, P., Hu, C, Williams, D., 2008. The development of a geospatial data Grid by integrating OGC Web services with Globus-based Grid technology. Concurrency and Computation: Practice and Experience. 20(14), $1617-1635$.

Di, L, Moe, K., Van, Z.L.T., 2010. Earth observation sensor web: An overview. Selected Topics in Applied Earth Observations and Remote Sensing. IEEE Journal. 3(4), 415-417.

Di, L., Yu, G., Shao, Y., Bai, Y., Deng, M., McDonald, K.R., 2010. Persistent WCS and CSW services of GOES data for GEOSS. Proc Geoscience and Remote Sensing Symposium (IGARSS), IEEE International. 1699-1702.

Dokas, I. M., Karras, D. A., \& Panagiotakopoulos, D. C., 2009. Fault tree analysis and fuzzy expert systems: early warning and emergency response of landfill operations. Environmental Modelling \& Software, 24(1), 8-25. 
Fang, Y., Lee, B., Chou, T., Lin, Y., Lien, J., 2009. The implementation of SOA within grid structure for disaster monitoring. Expert Systems with Applications. 36(3), 5784-5792.

Franklin, S., Graesser, A., 1997. Is it an Agent, or just a Program?: A Taxonomy for Autonomous Agents. Intelligent agents III agent theories, architectures, and languages. Springer Berlin Heidelberg. 21-35.

Gray, R.S., Cybenko, G., Kotz, D., Peterson, A.R., Rus, D., 2002. D'Agents: Applications and performance of a mobile-agent system. Software: Practice and Experience. 32(6), 543-573.

Hewitt, C. (1977), "Viewing Control Structures as Patterns of Passing Messages", Artificial Intelligence 8(3), $323-364$.

Hwang, S., Lim, E.P., Lee, C-H., Chen, C-H., 2008. Dynamic Web service selection for reliable Web service composition. IEEE Transactions on Services Computing. 1(2), 104-116.

Huang, A.F.M., Lan, C.W., Yang, S.J.H, 2009. An optimal QoS-based Web service selection scheme. Information Sciences. 179(19), 3309-3322.

Hadad, J.E., Manouvrier, M., Rukoz, M., 2010. TQoS: Transactional and QoS-Aware Selection Algorithm for Automatic Web Service Composition. IEEE Trans Services Computing. 3(1), 73-85.

Huang, Q., Yang, C., Liu, K., Xia, J., Xu, C., Li, J., Gui, Z, Sun, M, Li, Z, 2013. Evaluating open-source cloud computing solutions for geosciences. Computers \& Geosciences. 59, 41-52.

Huang, Q, Yang, C, Benedict, K., Chen, S, Rezgui, A., Xie, J, 2013. Utilize cloud computing to support dust storm forecasting. International Journal of Digital Earth. 6(4), 338-355.

Havlik, D., Schade, S., Sabeur, Z.A., Mazzetti, P., Watson, K., Berre, A.J., Mon, J.L., 2011. From sensor to observation web with environmental enablers in the future internet. Sensors. 11(4), 3874-3907.

Henzen, C., Brauner, M., Müller, D.H., and Bernard, L., 2015. Geoprocessing Appstore." Proceedings of the 18th AGILE international conference on geographic information sciences, Lisboa, Portugal. 2015.

Ibrahim, N., Michail, M., Callaghan, P., The strengths based approach as a service delivery model for severe mental illness: a meta-analysis of clinical trials. BMC psychiatry, 2014, 14(1): 243.

Jennings, N.R., On agent-based software engineering. Artificial intelligence, 2000, 117(2), 277-296.

Kauker, F., Kaminski, T., Karcher, M., Dowdall, M., Brown, J., \& Hosseini, A., et al., 2016. Model analysis of worst place scenarios for nuclear accidents in the northern marine environment. Environmental Modelling \& Software, 77, 13-18.

Klien, E., Lutz, M., Kuhn, W., 2006. Ontology-based discovery of geographic information services-An application in disaster management. Computers, environment and urban systems. 30(1), 102-123.

Li, Z., Yang, C., Huang, Q., Liu, K., 2014. Building Model as a Service to support geosciences. Computers, Environment and Urban Systems.

Lehto, J., Rajamäki, J., Rathod, P., 2012. Cloud computing with SOA approach as part of the disaster recovery and response in Finland. International Journal of Computers and Communication. 3(6), 175-182.

Leskens, J.G., Brugnach, M., Hoekstra, A.Y., Schuurmans, W., 2014. Why are decisions in flood disaster management so poorly supported by information from flood models?. Environmental modelling \& software. 53, 53-61.

Luo, J., Xu, L., Jamont, J.P., Li, Z., Shi, Z., 2007. Flood decision support system on agent grid: method and implementation. Enterprise Information Systems. 1(1), 49-68.

Lloyd, W., David, O., Lyon, J., Rojas, K.W., Ascough, J.C., Green, T.R., Carlson, J.R., 2012. The Cloud Services Innovation Platform-Enabling Service-Based Environmental Modelling Using Infrastructure-as-a-Service Cloud Computing. International Environmental Modelling and Software Society.

Muller, I., Kowalczyk, R., Braun, P., 2006. Towards agent-based coalition formation for service composition. Proc IAT. 73-80.

Mell, P.M., Grance, T., 2009. The NIST definition of cloud computing. National Institute of Standards and Technology. 53(6): 50.

Nwana, Hyacinth S., 1996. Software Agents: An Overview. Knowledge Engineering Review, Vol. 11, No 3, pp.1-40, Sept 1996.

Oh, S., Lee, D., Kumara, S.R.T., 2007. Web service planner (WsPr): an effective and scalable Web service composition algorithm. Journal of Web Services Research. 4(1), 1-23.

Oz, R.G., Arnon, B.E., Dahan U., 2012. SOA patterns. CA: Manning. 211-232.

Parkera, D.C., Mansonb, S.M., Janssenc, M.A., Hoffmannd, M.J., Deadmane, P., 2003. Multi-Agent Systems for the Simulation of Land-Use and Land-Cover Change: A Review. Annals of the Association of American Geographers. 93(2), 314-337.

Pasley, J., 2005. How BPEL and SOA are changing Web services development. Internet Computing. 9(3), 60-67.

Peng C., Deng M., Di L. \& W. Han (2015). Delivery of agricultural drought information via web services. Earth Sci Inf. doi:10.1007/s12145-014-0198-7.

Perera, C., Zaslavsky, A., Christen, P., Georgakopoulos, D., 2014. Sensing as a service model for smart cities supported by internet of things. Transactions on Emerging Telecommunications Technologies. 25(1), 81-93.

Quinn, N. W. T., \& Jacobs, K. C., 2007. Design and implementation of an emergency environmental response system to protect migrating salmon in the lower san joaquin river, california. Environmental Modelling \& Software, 22(4), 416-422.

Rajib, M. A., Merwade, V., Kim, I. L., Zhao, L., Song, C., \& Zhe, S., 2015. Swatshare - a web platform for collaborative research and education through online sharing, simulation and visualization of swat models. Environmental Modelling \& Software, 75, 498-512.

Rajamäki, J., Rathod, P., 2014. How standardized Utility Cloud Services and Service-oriented Architecture benefits in Public Protection and Disaster Relief?. International Journal of Computers and Communications. 8, 86-93. 
Sadler, J., Ames, D.P., and Khattar, R., 2016. A Recipe for Standards-Based Data Sharing using Open Source Software and Low-Cost Electronics. J. Hydroinformatics, 18(2), pp. 185-197.

Samarasinghe, S., \& Strickert, G., 2013. Mixed-method integration and advances in fuzzy cognitive maps for computational policy simulations for natural hazard mitigation. Environmental Modelling \& Software, 39(39), 188-200.

Sivashanmugam, K., Miller, J.A., Sheth, A. P.,Verma, K., 2004. Framework for semantic Web process composition. Journal of Electronic Commerce. 9(2), 71-106.

Sayar, A., Pierce, M., Fox, G.C., 2005.OGC Compatible Geographical Information Systems Web Services. Indiana Computer Science Technical Report TR610.

Schroth C., Janner T., 2007. Web 2.0 and SOA: Converging Concepts Enabling the Internet of Services. IT Professiona. 9(3), 36-41.

Shao, Y, Di, L, Gong, J, Bai, Y, Zhao, P.2011. GIS in the cloud: implementing a web coverage service on Amazon cloud computing platform, Electrical Engineering and Control. Springer Berlin Heidelberg. 289-295.

Shao, Y., Di, L., Bai, Y., Guo, B., Gong, J, 2012.Geoprocessing on the Amazon cloud computing platform-AWS. In Agro-Geoinformatics (Agro-Geoinformatics), 2012 First International Conference on (pp. 1-6). IEEE.

Sengupta, R., Bennet, D. A., 2003.Agent-based modelling environment for spatial decision support. International Journal of Geographical Information Science. 17(2), 157-180.

Schreinemachers, P., Berger, T., 2011. An agent-based simulation model of human-environment interactions in agricultural systems. Environmental Modelling \& Software. 26(7), 845-859.

Sawyer P., (ed.) ,2005. State of the Art - Service Engineering (Specification). Deliv-erable A1.D1a of the EU Integrated Project SeCSE.

Swain, N. R., Latu, K., Christensen, S. D., Jones, N. L., Nelson, E. J., \& Ames, D. P., et al., 2015. A review of open source software solutions for developing water resources web applications. Environmental Modelling \& Software, 67, 108-117.

Tang, W., Wang, S., Bennett D.A., Liu Y., 2011. Agent-based modeling within a cyberinfrastructure environment: a service-oriented computing approach. International Journal of Geographical Information Science. 25(9), 1323-1346.

Tan, X., Di, L., Deng, M., Chen, A., Huang, F., Peng, C., Gao, M.; Yao, Y., Sha, Z., 2015. Cloud-and Agent-Based Geospatial Service Chain: A Case Study of Submerged Crops Analysis During Flooding of the Yangtze River Basin. IEEE Journal of Selected Topics in Applied Earth Observations and Remote Sensing. 8(3), 1359-1370.

Tralli, D. M., Blom, R. G., Zlotnicki, V., Donnellan, A., \& Evans, D. L., 2005. Satellite remote sensing of earthquake, volcano, flood, landslide and coastal inundation hazards. Isprs Journal of Photogrammetry \& Remote Sensing, 59(4), 185-198.

Usländer, T., Jacques, P., Simonis, I., Watson, K., 2010. Designing environmental software applications based upon an open sensor service architecture. Environmental Modelling \& Software. 25(9), 977-987.

Van J A A, Mckeown D, Faulring J W., 2010. Geospatial disaster response during the Haiti earthquake: A case study spanning airborne deployment, data collection, transfer, processing, and dissemination[J]. Photogrammetric Engineering \& Remote Sensing, 77(77):943-952.

Vescoukis, V., Doulamis, N., Karagiorgou, S., 2012. A service oriented architecture for decision support systems in environmental crisis management. Future generation computer systems. 28(3), 593-604.

Voinov, A., Bousquet, F., 2010. Modelling with stakeholders. Environmental Modelling \& Software, 25(11), 1268-1281.

Wächter, J., Babeyko, A., Fleischer, J., Häner, R., 2012. Development of tsunami early warning systems and future challenges. Natural Hazards and Earth System Science. 12(6), 1923-1935.

Wan, Z., Hong, Y., Khan S., Gourleyc, J., Flamig, Z., Kirschbaum, D., Tang, G, 2014. A cloud-based global flood disaster community cyber-infrastructure: Development and demonstration. Environmental Modelling \& Software. 58, 86-94.

Wang, L, Kunze, M., Tao, J, Laszewski, G V., Towards building a cloud for scientific applications. Advances in Engineering Software, 2011, 42(9):714-722.

Wang, L., Chen, D., Hu, Y., Ma, Y., Wang, J., Towards enabling Cyberinfrastructure as a Service in Clouds. Computers \& Electrical Engineering, 2013, 3(9):3-14.

Wang, L., Laszewski, G.V., Younge, A., He, X., Kunze, M., Tao, J, Fu, C. Cloud Computing: a Perspective Study. New Generation Computing, 2010, 28(2):137-146.

Wang Q., Wang J., 2009. Intelligent Web Map Service Aggregation. Proc. 2009 International Conference on Computational Intelligence and Natural Computing. 2, 229-231.

Xiong, H., Zhang, Daqiang, Zhang, Daqing, Gauthier, V., Yang, K, Becker,M., 2014. MPaaS: Mobility prediction as a service in telecom cloud. Information Systems Frontiers. 16(1), 59-75.

Xu, J., Nyerges, T. L., \& Nie, G., 2014. Modeling and representation for earthquake emergency response knowledge: perspective for working with geo-ontology. International Journal of Geographical Information Science, 28(1), 185-205.

Xu, Q., Yu, Z., 2006. Web Service Composition Based On Mobile Agent And Active Network. Communications, Circuits and Systems Proceedings. 3.

Yue, P., Di, L., Yang, W., Yu, G., Zhao, P., 2007. Semantics-based automatic composition of geospatial Web service chains. Computers \& Geosciences. 33(5), 649-665.

Yue, P., Gong J., Di L., 2010. Augmenting geospatial data provenance through metadata tracking in geospatial service chaining. Computers \& Geosciences. 36(3), 270-281. 
Yue, P., Zhou, H., Gong, J., Hu, L., 2012. Geoprocessing in Cloud Computing platforms - a comparative analysis. Cloud Computing. 6(4), 404-425.

Yu, G., Zhao, P., Di, L., Chen, A., Deng, M., Bai, Y., 2012. BPELPower-A BPEL execution engine for geospatial web services. Computers \& Geosciences. 47, 87-101.

Yang, C., Raskin, R., 2009. Introduction to distributed geographic information processing research. International Journal of Geographical Information Science. 23(5), 553-560.

Yang, C., Goodchild, M., Huang, Q., Nebert, D., Raskin, R., Xu Y., Bambacus, M., Fay, D., 2011. Spatial cloud computing: how can the geospatial sciences use and help shape cloud computing. International Journal of Digital Earth. 4(4), 305-329.

Yang, C., Shao, Y., Chen, N., Di, L., 2012. The cloud computing for a dynamic agro-geoinformation processing[C]//Agro-Geoinformatics (Agro-Geoinformatics), 2012 First International Conference on. IEEE. 1-4.

Yang, C., Xu, Y., Nebert, D., 2013. Redefining the possibility of digital Earth and geosciences with spatial cloud computing. International Journal of Digital Earth. 6(4), 297-312.

Zhao, P., Yu, G., Di, L., 2007. Geospatial web services. Emerging Spatial Information Systems and Applications. 1-35.

Zhao, P., Di, L., Yu, G., Yue, P., Wei, Y., Yang, W., 2009. Semantic Web-based geospatial knowledge transformation. Computers \& Geosciences. 35(4), 798-808. 
